\title{
A Statistical-Dynamical Downscaling for the Urban Heat Island and Building Energy Consumption-Analysis of Its Uncertainties ?
}

\author{
ROBERT SCHOETTER \\ CNRM, Université de Toulouse, Météo France, CNRS, Toulouse, France \\ Julia HidAlgo AND RENAUd JOUGLA \\ Laboratoire Interdisciplinaire Solidarités, Sociétés, Territoires, Toulouse II University/CNRS, Toulouse, France \\ VALÉRY MASSON \\ CNRM, Université de Toulouse, Météo France, CNRS, Toulouse, France \\ Mario Rega And Julien Pergaud \\ Biogéosciences UMR 6282, CNRS/Université de Bourgogne Franche-Comté, Dijon, France
}

(Manuscript received 24 July 2019, in final form 9 March 2020)

\begin{abstract}
High-resolution maps of the urban heat island (UHI) and building energy consumption are relevant for urban planning in the context of climate change mitigation and adaptation. A statistical-dynamical downscaling for these parameters is proposed in the present study. It combines a statistical local weather type approach with dynamical simulations using the mesoscale atmospheric model Meso-NH coupled to the urban canopy model Town Energy Balance. The downscaling is subject to uncertainties related to the weather type approach (statistical uncertainty) and to the numerical models (dynamical uncertainty). These uncertainties are quantified for two French cities (Toulouse and Dijon) for which long-term dense high-quality observations are available. The seasonal average nocturnal UHI intensity is simulated with less than $0.2 \mathrm{~K}$ bias for Dijon, but it is overestimated by up to $0.8 \mathrm{~K}$ for Toulouse. The sensitivity of the UHI intensity to weather type is, on average, captured by Meso-NH. The statistical uncertainty is as large as the dynamical uncertainty if only one day is simulated for each weather type. It can be considerably reduced if 3-6 days are taken instead. The UHI reduces the building energy consumption by $10 \%$ in the center of Toulouse; it should therefore be taken into account in the production of building energy consumption maps.
\end{abstract}

\section{Introduction}

\section{a. Background}

Weather and climate impact transportation, water resources management, agriculture, and urban planning. These impacts must be quantified at a small spatial scale (e.g., a motorway, vineyard, or building block). Meteorologists and climate scientists are therefore

Supplemental information related to this paper is available at the Journals Online website: https://doi.org/10.1175/JAMC-D-190182.s1.

Corresponding author: Robert Schoetter, robert.schoetter@ meteo.fr often confronted with requests for meteorological parameters at a spatial resolution that cannot be achieved by state-of-the-art weather forecast or Earth system models.

Downscaling techniques have been developed to derive meteorological parameters at high spatial resolution from low-resolution numerical simulations or sparse observations (Rummukainen 2010). Three categories of downscaling exist: 1) Statistical downscaling is based on relationships between large-scale predictors (e.g., atmospheric circulation patterns) and localscale predictants (e.g., precipitation at a station) (Wilby et al. 2009). While it is computationally efficient, it does not preserve physical consistency between parameters, relies on observational data for calibration, and assumes 
that the statistical relationships are constant (e.g., between historical and future climate). 2) Dynamical downscaling consists of forcing a high-resolution atmospheric model (e.g., a regional climate model; Jacob et al. 2014) with results from a lower-resolution model (e.g., an Earth system model). Dynamical downscaling is independent of observations and preserves the physical consistency between meteorological parameters. Its disadvantages are the high computational cost and the difficulty to correct for biases of the coarse-resolution model. 3) Statistical-dynamical downscaling (SDD; Frey-Buness et al. 1995) is a combination of statistical and dynamical downscaling. It assumes that the small-scale meteorological phenomenon of interest depends on the meteorological situation. Relevant meteorological situations are selected and short-term (e.g., a few hours, a few days) highresolution numerical simulations are conducted. SDD allows the use of a physically based atmospheric model while keeping the computational cost reasonably low.

SDD has been applied frequently to wind (Mengelkamp et al. 1997; Najac et al. 2011; Martinez et al. 2013; Svoboda et al. 2013; Badger et al. 2014) and precipitation in complex terrain such as that of the Alpine region (Frey-Buness et al. 1995; Fuentes and Heimann 2000), central Asia (Reyers et al. 2013), and Vietnam (Tran Anh and Taniguchi 2018). SDD has been further applied to winter storms (Pinto et al. 2010), ocean modeling (Cassou et al. 2011), and the urban heat island effect (Hoffmann et al. 2018). SDD is thus mainly applied to meteorological phenomena, which are strongly influenced by the prevailing complex topography. The benefit of employing a physically based high-resolution numerical model is highest in these applications.

SDD is subject to two different types of uncertainty. On the one hand there is the uncertainty due to biases in the large-scale meteorological data or the highresolution numerical model, hereafter referred to as the "dynamical" uncertainty. On the other hand, there is the uncertainty due to the use of a limited number of meteorological situations rather than a climatological time series (e.g., 30 years), hereafter referred to as the "statistical" uncertainty. For any given meteorological situation, there may be nonnegligible variability of the small-scale parameter of interest. Boé and Terray (2008), for example, found large differences in precipitation intensity for nearly identical large-scale meteorological situations. Previous studies have investigated the relative importance of the dynamical and statistical uncertainty, but never in relation to urban climatology. Fuentes and Heimann (2000) and Reyers et al. (2013) conclude that the dynamical uncertainty dominates for precipitation in the Alpine region and central Asia, respectively. Najac et al. (2011) found that for near-surface wind in France, the dynamical uncertainty dominates for mountainous areas, whereas the statistical uncertainty dominates in largely flat northwestern France.

Urban areas are characterized by strongly heterogeneous topography and exhibit a different local climate than surrounding rural areas. This is due to the differences of the surface balances of energy, water, and momentum (Oke et al. 2017) between urban and rural areas. Urban areas are usually less vegetated than rural areas, leading to less evapotranspiration during the day. The storage of heat in construction materials leads to a larger daily amplitude of the storage heat flux. Further, three-dimensional building geometry leads to shading of solar radiation and traps infrared radiation. Human activities also release heat and moisture (Sailor 2011). The most widely described urban climate phenomenon is the higher air temperature in urban areas compared to rural areas: the urban heat island effect (UHI). It is usually most pronounced during the evening and night and can reach an intensity of 5 to $10 \mathrm{~K}$ (Oke 1973) under favorable meteorological conditions. The UHI negatively impacts human thermal comfort and health (Gabriel and Endlicher 2011) during warm weather situations and interacts with building energy consumption. It reduces (increases) the energy consumption for heating (air conditioning).

\section{b. Present study}

The present study is conducted within the framework of the French Applied Modeling and Urban Planning Law: Climate and Energy (MApUCE) project, which aims to provide information on urban morphology and indicators characterizing the urban climate and building energy consumption for a selection of about 50 large French urban agglomerations. The first objective is to propose an SDD for the UHI and building energy consumption to be used to produce these indicators, and to discuss its uncertainties. The second objective is to quantify the statistical and dynamical uncertainty for two French cities (Toulouse and Dijon) for which long-term high-quality observations of urban nearsurface air temperature are available.

The SDD is based on the previous work of Hoffmann et al. (2018), who used the simulated UHI patterns from short-term numerical simulations for different meteorological situations to estimate the climatological UHI pattern. This method is suitable for the UHI (the urban-rural temperature difference), but not for the quantification of thermal climate indicators (e.g., the number of hot days) or building energy consumption, which depend on the absolute value of air temperature. Therefore, computationally cheap long-term integrations of an urban canopy model in offline mode are conducted 


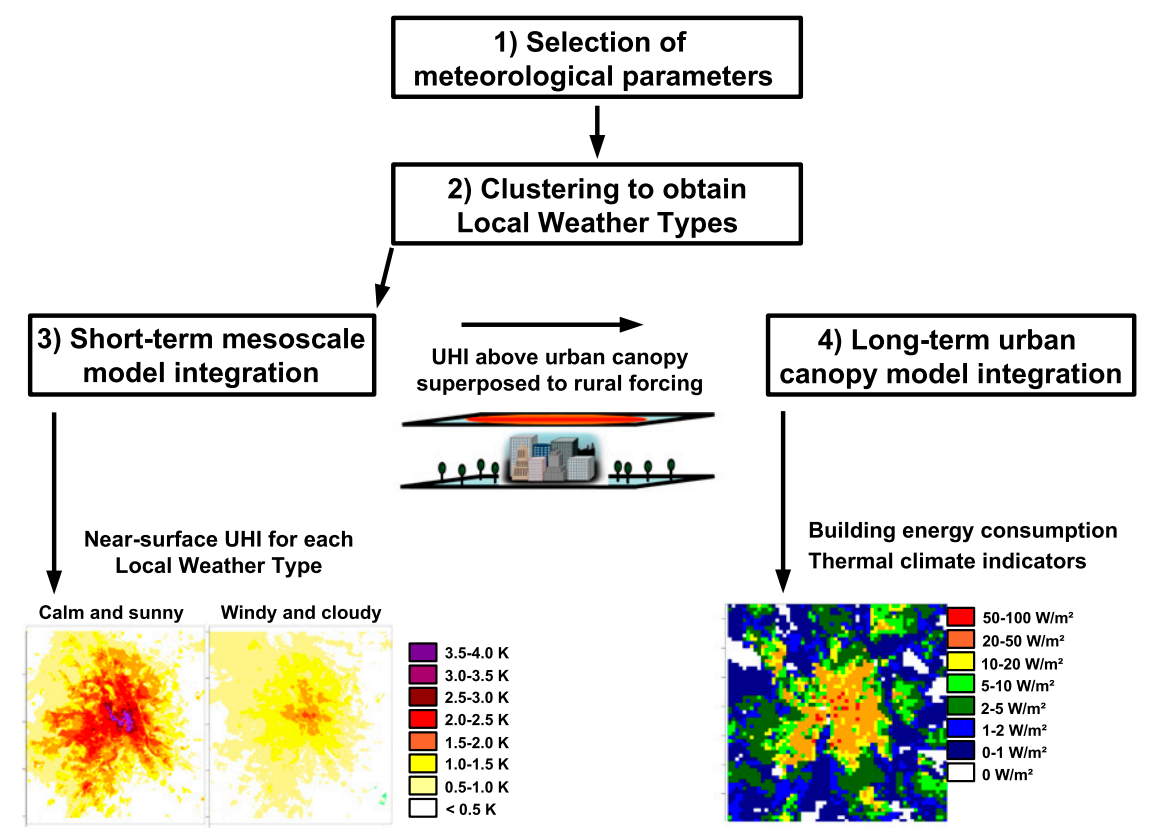

FIG. 1. The statistical-dynamical downscaling methodology.

here. Following Lemonsu et al. (2013), the urban heat island patterns obtained from short-term integrations are superposed on the rural forcing to construct forcing data representative for the urban boundary layer. The long-term integrations allow the spatial distribution of thermal climate indicators and building energy consumption in the urban area to be quantified.

Section 2 provides a general description of the proposed SDD, and a discussion of its uncertainties. The model configuration and the employed datasets are described in section 3 , the results in section 4 . Conclusions are drawn in section 5 .

\section{Statistical-dynamical downscaling for the UHI and building energy consumption}

\section{a. The proposed statistical-dynamical downscaling}

In the following, the observed or simulated difference of air temperature between urban and rural areas is denoted with UHI, whereas the air temperature difference between a numerical model simulation including urbanization effects and a simulation without urbanization is denoted with urban influence on air temperature (UI). The proposed SDD for the UHI and building energy consumption consists of 4 steps (Fig. 1):

1) Selection of meteorological parameters relevant for the UHI.

2) Identification of local weather types (LWT) by clustering the meteorological parameters.
3) High-resolution short-term numerical integration of a mesoscale atmospheric model coupled to an urban canopy model for the selected LWT to calculate the UHI and UI.

4) Long-term numerical integration of the urban canopy model in offline mode using the UI patterns from the short-term integrations to calculate thermal climate indicators and building energy consumption.

\section{1) Selection of meteorological PARAMETERS}

The basic assumption of the SDD is that the UHI depends on the local meteorological conditions. This is justified by the well-established links between the UHI intensity and the prevailing wind speed, cloud cover, relative humidity, and pressure (Oke et al. 2017). The UHI intensity is lower for higher wind speed, since there is more turbulent mixing and more advection processes between urban and rural areas. It is also lower for higher relative humidity and cloud cover, since for such situations there is less downwelling solar radiation during the day and more downwelling terrestrial radiation at night. The wind direction is relevant to the spatial pattern of the UHI. The SDD proposed in the present study relies on daily values of wind speed $(\overline{\mathrm{FF}})$, direction $(\overline{\mathrm{DD}})$, specific humidity $(\bar{Q})$, precipitation (RR), and daily temperature range $(\Delta T)$. These can be obtained from a routine observation station or numerical model output representative for the rural areas close to the urban 
area of investigation. Numerical model output can be representative for both historical and future climate conditions.

\section{2) IDENTIFICATION OF LWT}

A clustering of the meteorological parameters described in Hidalgo et al. (2014) and Hidalgo and Jougla (2018) is made to assign each day to a LWT. The LWT describe the series of states of the atmosphere above a location in their usual succession that define its local climate. The notion of local means here the atmospheric conditions representative of the background rural area surrounding the city. To identify how many LWT are needed to describe the local climatology, an iterative procedure increasing the number of LWT is performed. There are different ways to quantify the resulting clustering quality to fix the optimal number of LWT. Hidalgo et al. (2014) defined the clustering quality by evaluating the hourly time series of the meteorological parameters.

LWT are more suitable for the UHI than synoptic- or hemispheric-scale circulation regimes, since the UHI is mainly shaped by the meteorological conditions in and around the immediate vicinity of the city. Hoffmann and Schluenzen (2013), for example, found that synoptic-scale weather patterns explain only about $15 \%$ of the UHI intensity variance for Hamburg, Germany, whereas the combination of these weather patterns with local-scale meteorological parameters explains about $50 \%$ of the UHI variance (Hoffmann et al. 2018). Every LWT is characterized by its so-called centroid day. The partitioning around medoids (PAM) classification algorithm assigns cluster centroids, which are actual elements of the ensemble to be clustered. This is not the case for algorithms like $k$-means, which aggregate elements around fictitious points corresponding to the average of the cluster. Below, "centroid day" denotes the actual cluster centroid for a classification algorithm like PAM and the day closest to the cluster centroid for an algorithm like $k$-means. It is further assumed that, independently of the LWT, the UHI needs to be dynamically simulated in all seasons of the year, since different physical processes can be relevant. Solar radiation, the main driver of the surface energy balance, varies through the seasons. In the cold (warm) season, heating (air conditioning) might contribute to the urban energy balance. Depending on the climatic region, vegetation may be more active in different seasons. An exception could be made for a city in a tropical climate with nearly no seasonal difference in meteorological conditions.

\section{3) HigH-RESOLUTION SHORT-TERM NUMERICAL INTEGRATIONS OF ATMOSPHERIC MODEL}

Short-term numerical integrations using a mesoscale atmospheric model are carried out for the selected
LWT. They must be conducted for at least one day for each LWT and season, typically the centroid day. More days can be simulated to reduce the uncertainty due to intracluster variability. Independently of the number of days representing each LWT, a spinup of one or two days before each day of investigation is required due to the high thermal inertia of the urban materials. The mesoscale model should include a stateof-the-art urban canopy model to take into account the specifics of the urban energy balance. The numerical simulations provide the spatial distribution of the UHI in the urban canopy layer (e.g., at $2 \mathrm{~m}$ above ground), and on top of the urban roughness sublayer, which is located at about 2-5 times the average building height (Roth 2007). The results provide information on the UHI intensity and pattern for different meteorological situations, such as summer situations with a risk for heat stress and winter situations with large heating energy consumption and a risk of road icing.

The so-called nourban simulations are performed to calculate the urban influence on simulated air temperature [UI ${ }^{\operatorname{sim}}(x, d)$; Eq. (1)]. For the "nourban" simulations, the urban areas are replaced with a land surface cover typical for the rural areas surrounding the city:

$$
\mathrm{UI}^{\mathrm{sim}}(x, d)=T_{\mathrm{urb}}^{\mathrm{sim}}(x, d)-T_{\text {nourb }}^{\mathrm{sim}}(x, d),
$$

where $T^{\text {sim }}$ denotes the simulated air temperature, $x$ denotes the space coordinate, and $d$ denotes one day. The UHI is usually characterized by a daily cycle with the largest values in the evening and night and lowest values in the morning. For this reason, daily time segments of $\mathrm{UI}^{\mathrm{sim}}$, rather than daily average values, should be taken. The nocturnal UHI can be shaped by the meteorological conditions prevailing on the preceding day (e.g., Hoffmann et al. 2012). Therefore, the daily time segments should not start at midnight, but rather in the morning, when the UHI is minimal or slightly negative (e.g., Hidalgo et al. 2008). In the present study, we limit our discussion to the superposition of the urban influence on air temperature to the rural forcing data. However, other meteorological parameters can also be influenced by urban areas. Relative humidity is usually lower, mainly because air temperature is higher. If the urban canopy model is forced with specific or absolute humidity, this effect is considered implicitly via the higher air temperature in the forcing. Specific or absolute humidity is usually only slightly different between urban and rural areas. Downwelling (nocturnal) longwave radiation might be systematically higher in urban areas due to the higher (nocturnal) air temperature in the urban boundary layer. This could be taken into account but is not investigated in the present 
study. Downwelling shortwave radiation and precipitation can also be modified by the urban area, but the patterns of differences cannot be expected to be statistically significant using short-term numerical integrations alone.

\section{4) LONG-TERM NUMERICAL INTEGRATION OF THE URBAN CANOPY MODEL IN OFFLINE MODE}

The selection of LWT is tailored to the UHI, the temperature difference between urban and rural areas. The LWT are not strongly related to the absolute value of air temperature. The results from the short-term numerical integrations alone are therefore not suitable for calculating climatological averages of thermal climatic indicators. Such are the spatial distribution in the urban area of the frequency of hot days $\left(T_{\max }>30^{\circ} \mathrm{C}\right)$, tropical nights $\left(T_{\min }>20^{\circ} \mathrm{C}\right)$, or the energy consumption for heating and air conditioning. These indicators cannot be derived from statistical recombination of the results from the short-term numerical integrations only. For this reason, the SDD is extended by long-term integrations (e.g., 10-30 years) of the urban canopy model in so-called offline mode. In such computationally cheap simulations, the urban canopy model is forced by meteorological parameters representative for the top of the urban roughness sublayer. Forcing data can be obtained from numerical model output (e.g., from analysis or reanalysis data) or routine observation data representative for the rural areas surrounding the city. For routine observation data, observed air temperature (wind speed) at $2 \mathrm{~m}(10 \mathrm{~m})$ above ground must be extrapolated to the forcing height, for example as described by Lemonsu et al. (2013). To account for the urban influence on air temperature above the urban roughness sublayer $\left(T_{\text {urb }}\right)$, the spatial pattern of the simulated UI at this height is superposed to the rural forcing data $\left(T_{\text {rur }}\right)$. The 10-30-yr time series of UI is not known, since the short-term numerical integrations cover only one or few days for each LWT. Based on the short-term integrations, an estimation of the UI for each season (seas) and LWT $[k(d)]\left[\widehat{\mathrm{UI}}_{\text {seas, }, k(d)}^{\text {sim }}(x)\right.$; Eq. (2)] is calculated, where $k(d)$ denotes the daily time series of the LWT. Different methods to estimate $\widehat{\mathrm{UI}}$ and the related uncertainties will be discussed in the following section:

$$
\forall(\text { seas }, k) T_{\text {urb }}(x, d)=T_{\text {rur }}(x, d)+\widehat{\mathrm{UI}}_{\text {seas }, k(d)}^{\text {sim }}(x) .
$$

\section{b. Uncertainties of the statistical-dynamical downscaling}

The uncertainties of the SDD are due to the weather typing approach (statistical uncertainty), potential biases of the numerical model (dynamical uncertainty), and application to very complex topography or future climate. In this section, the quantification of the statistical and dynamical uncertainty is described, assuming that long-term high-quality urban observations and longterm numerical integrations of a high-resolution model are available. The uncertainties due to heterogeneous topography and potential SDD application in future climate are briefly described, but will not be further investigated in the present study.

\section{1) StatisticAl UnCERTAinTY}

The statistical uncertainty quantified here corresponds to that which results from the reconstruction of the full time series of the simulated urban influence on air temperature $\left[\mathrm{UI}^{\mathrm{sim}}(x, d)\right.$, the "reference"] from the results of the short-term numerical integrations for a reduced number of LWT. In this section, the uncertainty arising from this reconstruction for different estimators of the UI pattern per LWT [ $\left.\widehat{\mathrm{UI}}_{\text {seas }, k(d)}^{\text {sim }}(x)\right]$ is analyzed. The yearly mean UI [UI ${ }^{\operatorname{sim}}(x)$; Eq. (3)], the seasonal mean UI $\left[\overline{\mathrm{UI}_{\text {seas }}^{\text {sim }}(x)} ;\right.$ Eq. (4)] and the mean UI for one $\operatorname{LWT}\left(\mathrm{WT}_{k}\right)$ and season $\left[\mathrm{UI}_{\text {seas }, k}^{\text {sim }}(x)\right.$; Eq. (5)] are defined:

$$
\begin{aligned}
\overline{\mathrm{UI}^{\mathrm{sim}}(x)} & =\frac{1}{N_{d}} \sum_{d} \mathrm{UI}^{\mathrm{sim}}(x, d), \\
\overline{\mathrm{UI}_{\text {seas }}^{\text {sim }}(x)} & =\frac{1}{N_{\text {seas }}} \sum_{d \in \text { seas }} \mathrm{UI}^{\mathrm{sim}}(x, d), \quad \text { and } \\
\overline{\mathrm{UI}_{\text {seas }, k}^{\text {sim }}(x)} & =\frac{1}{N_{\text {seas }, k}} \sum_{d \in(\text { seas }, k)} \mathrm{UI}^{\text {sim }}(x, d) .
\end{aligned}
$$

In Eqs. (3)-(5), $N_{d}$ denotes the total number of days, $N_{\text {seas }}$ denotes the number of days in a season, and $N_{\text {seas, } k}$ denotes the number of days of LWT $k$ in a season. The uncertainty of the reconstructed time series of UI is quantified by calculating the spatial bias [Eq. (6)] and spatial root-mean-square error [rmse; Eq. (7)]. The seasonal average UI patterns are calculated using the seasonal frequencies of the LWT $\left(f_{k}\right)$ as weights [Eq. (8)]. The seasonal pattern correlation ( paco $_{\text {seas }}$ ) between the reconstructed and reference UI patterns [Eq. (9)] quantifies the degree of agreement between the reconstructed and reference UI patterns:

$$
\operatorname{bias}(x)=\frac{1}{N_{d}} \sum_{d} \forall(\text { seas }, k)\left[\widehat{\mathrm{UI}_{\text {seas }, k(d)}^{\text {sim }}(x)}-\mathrm{UI}^{\text {sim }}(x, d)\right],
$$

$$
\operatorname{rmse}(x)=\sqrt{\frac{1}{N_{d}} \sum_{d} \forall(\text { seas }, k)\left[\widehat{\mathrm{UI}_{\text {seas }, k(d)}^{\text {sim }}(x)}-\mathrm{UI}^{\text {sim }}(x, d)\right]^{2}},
$$




$$
\begin{aligned}
& \overline{\overline{\mathrm{UI}_{\text {seas }}^{\text {sim }}(x)}}=\sum_{k=1}^{N_{\mathrm{WT}}} f_{\bar{k}}^{\overline{\mathrm{UI}_{\text {seas }, k}^{\text {sim }}(x)}}, \quad \text { and } \\
& \text { paco }_{\text {seas }}=\operatorname{cor}\left[\overline{\overline{\mathrm{UI}_{\text {seas }}^{\text {sim }}(x)}}, \overline{\mathrm{UI}_{\text {seas }}^{\text {sim }}(x)}\right] \text {; }
\end{aligned}
$$

$N_{\text {WT }}$ denotes the number of LWT, and cor denotes the Pearson correlation coefficient.

In the following, two possible methods are introduced to specify $\widehat{\mathrm{UI}}_{\text {seas }, k(d)}^{\text {sim }}(x)$. In both methods, $\widehat{\mathrm{UI}}_{\text {seas }, k(d)}^{\text {sim }}(x)$ can be obtained from a small number of short-term numerical integrations:

- WT-CENT-UI: UI corresponds to the daily cycle simulated for the LWT centroid day $d_{\text {seas, } k}^{c}[\forall$ (seas, k) $\left.\widehat{\mathrm{UI}}_{\text {seas }, k(d)}^{\text {sim }}(x)=\mathrm{UI}^{\mathrm{sim}}\left(x, d_{k, \text { seas }}^{c}\right)\right]$.

- WT-NDAY-UI: UI corresponds to the mean daily cycle for the LWT centroid day and $N-1$ randomly selected additional days $\left\{\forall(\right.$ seas, $k) \widehat{U I}_{\text {seas }, k(d)}^{\text {sim }}(x)=$ $\left.(1 / N)\left[\mathrm{UI}^{\mathrm{sim}}\left(x, d_{k, \text { seas }}^{c}\right)+\sum_{i=1}^{N-1} \mathrm{UI}^{\operatorname{sim}}\left(x, d_{i}\right)\right]\right\}$.

WT-CENT-UI corresponds to the assumption that every day belonging to one LWT is represented by the corresponding LWT centroid day. WT-NDAY-UI corresponds to an optimized version of WT-CENT-UI to reduce the uncertainty due to intracluster variability. The evaluation measures obtained for these two methods will be compared with three benchmarks:

- NO-UI is defined as neglecting the urban influence on air temperature [ $\forall($ seas, $\left.k) \widehat{\mathrm{UI}}_{\text {seas }, k(d)}^{\text {sim }}(x)=0\right]$.

- MEAN-UI is defined as using the average annual daily cycle of UI [ $\forall($ seas, $\left.k) \widehat{\mathrm{UI}_{\text {seas }}^{\text {sim }}(d)}(x)=\overline{\mathrm{UI}^{\mathrm{sim}}(x)}\right]$.

- WT-MEAN-UI is defined as using the average daily cycle of UI for each LWT $k$ and season $\left[\forall(\right.$ seas, $\left.k) \widehat{\mathrm{UI}}_{\text {seas }, k(d)}^{\text {sim }}(x)=\overline{\mathrm{UI}_{\text {seas }, k}^{\text {sim }}(x)}\right]$.

The bias for MEAN-UI and WT-MEAN-UI is 0 . The uncertainty of the reconstructed UI for the different estimators is related to the ratio between the inter- and intracluster variability, which can be quantified with the explained UI variation due to the clustering [EVC; Eq. (10)]:

$$
\mathrm{EVC}=\sum_{d=1}^{N_{d}} \frac{\left[\overline{\mathrm{UI}_{\mathrm{seas}(d), k(d)}^{\mathrm{sim}}(x)}-\overline{\mathrm{UI}^{\mathrm{sim}}(x)}\right]^{2}}{\left[\mathrm{UI}^{\mathrm{sim}}(x, d)-\overline{\mathrm{UI}^{\mathrm{sim}}(x)}\right]^{2}} .
$$

For $\mathrm{EVC}=1$, the UI is exactly the same for each day belonging to a given LWT. In this case, the reconstructed time series for WT-MEAN-UI, WT-CENTUI, and WT-NDAY-UI is identical to the reference (bias $=0$, rmse $=0$, paco $=1$ ). In the more realistic case of $0<\mathrm{EVC}<1, \mathrm{UI}^{\operatorname{sim}}(x)$ is not exactly the same for each day belonging to one LWT, and WT-MEAN-UI no longer corresponds to the reference (rmse $>0$ ). The UI simulated for the LWT centroid day [UI $\left.{ }^{\operatorname{sim}}\left(x, d_{k}^{c}\right)\right]$ can differ by a residual $\varepsilon(x)$ from $\overline{\mathrm{UI}_{\text {seas }, k}^{\text {sim }}(x)}$ due to intracluster variability [Eq. (11)]. The rmse for WT-CENT-UI will therefore be larger than for WT-MEAN-UI, and the bias and paco will differ from their optimum values (bias $\neq 0$, paco $<1$ ). For WTNDAY-UI, the bias, rmse, and paco will converge toward those for WT-MEAN-UI the more days are simulated per LWT:

$$
\mathrm{UI}^{\mathrm{sim}}\left(x, d_{\text {seas }, k}^{c}\right)=\overline{\mathrm{UI}_{\text {seas }, k}^{\text {sim }}(x)}+\varepsilon(x) .
$$

\section{2) DYNAMICAL UNCERTAINTY}

The dynamical uncertainty is related to potential shortcomings of the high-resolution atmospheric model in simulating the UHI for different LWT and seasons. It can only be quantified at those locations for which urban air temperature observations are available. Observation data might themselves be biased or unrepresentative for the spatial scale simulated by the numerical model. This further reduces the potential to quantify the dynamical uncertainty. The UHI is defined as temperature difference between an urban $\left(x_{\text {urb }}\right)$ and rural station $\left(x_{\text {rur }}\right)$ [Eq. (12)]:

$$
\mathrm{UHI}\left(x_{\mathrm{urb}}, d\right)=T\left(x_{\mathrm{urb}}, d\right)-T\left(x_{\mathrm{rur}}, d\right) .
$$

If sufficiently long time series of observed $\left(\mathrm{UHI}^{\mathrm{obs}}\right)$ and simulated $\left(\mathrm{UHI}^{\mathrm{sim}}\right)$ are available to calculate the mean UHI intensity per LWT and season, it is possible to quantify the dynamical uncertainty by comparing the simulated [Eq. (13)] and observed [Eq. (14)] average UHI intensity for each LWT and season:

$$
\begin{aligned}
& \overline{\mathrm{UHI}_{\text {seas }, k}^{\text {sim }}\left(x_{\text {urb }}\right)}=\frac{1}{N_{\text {seas }, k}} \sum_{d \in(\text { seas }, k)} \mathrm{UHI}^{\mathrm{sim}}\left(x_{\text {urb }}, d\right), \text { and } \\
& \overline{\mathrm{UHI}_{\text {seas }, k}^{\text {obs }}\left(x_{\text {urb }}\right)}=\frac{1}{N_{\text {seas }, k}} \sum_{d \in \text { (seas }, k)} \mathrm{UHI}^{\text {obs }}\left(x_{\text {urb }}, d\right)
\end{aligned}
$$

It is further quantified whether the differences between the LWT and seasonal average UHI intensity and the seasonal average UHI intensity are consistent between the numerical simulations and the observations [Eqs. (15) and (16)]. To objectively quantify this, the cluster difference consistency index [CDCI; Eq. (17)] is defined. CDCI is 1 for perfect agreement between simulated and observed UHI intensity differences and -1 for exactly opposite differences: 


$$
\Delta \mathrm{UHI}_{\text {seas }, k}^{\mathrm{sim}}\left(x_{\text {urb }}\right)=\overline{\mathrm{UHI}_{\text {seas }, k}^{\text {sim }}\left(x_{\text {urb }}\right)}-\overline{\mathrm{UHI}_{\text {seas }}^{\text {sim }}\left(x_{\text {urb }}\right)},
$$$$
\Delta \mathrm{UHI}_{\text {seas }, k}^{\mathrm{obs}}\left(x_{\text {urb }}\right)=\overline{\mathrm{UHI}_{\text {seas }, k}^{\mathrm{obs}}\left(x_{\text {urb }}\right)}-\overline{\mathrm{UHI}_{\text {seas }}^{\mathrm{obs}}\left(x_{\text {urb }}\right)},
$$

$$
\mathrm{CDCI}_{\text {seas }}=\sum_{k=1}^{N_{\mathrm{WT}}} f_{k}\left\{1-\frac{\left|\Delta \mathrm{UHI}_{\text {seas }, k}^{\text {sim }}\left(x_{\text {urb }}\right)-\Delta \mathrm{UHI}_{\text {seas }, k}^{\text {obs }}\left(x_{\text {urb }}\right)\right|}{\max \left[\left|\Delta \mathrm{UHI}_{\text {seas }, k}^{\text {sim }}\left(x_{\text {urb }}\right)\right|,\left|\Delta \mathrm{UHI}_{\text {seas }, k}^{\text {obs }}\left(x_{\text {urb }}\right)\right|\right]}\right\} .
$$

\section{3) CONTRIBUtion OF THE STATISTICAL AND DYNAMICAL UNCERTAINTY}

The contribution of the statistical and dynamical uncertainty is quantified by calculating the bias and rmse as defined in Eqs. (6) and (7) for three different estimators of the UHI [ $\left.\widehat{\mathrm{UHI}}_{\text {seas }, k(d)}\left(x_{\text {stat }}\right)\right]$.

- STAT: Statistical uncertainty arising from taking one single day per season to represent each LWT $\left[\forall(\right.$ seas, $\left.k) \widehat{\mathrm{UHI}}_{\text {seas }, k(d)}\left(x_{\text {stat }}\right)=\mathrm{UHI}^{\mathrm{obs}}\left(x_{\text {stat }}, d_{k}^{c}\right)\right]$.

- DYNA: Dynamical uncertainty only $[\forall($ seas, $k)$ $\left.\widehat{\mathrm{UHI}}_{\text {seas }, k(d)}\left(x_{\text {stat }}\right)=\mathrm{UHI}^{\mathrm{sim}}\left(x_{\text {stat }}, d\right)\right]$.

- STAT-DYNA: Combined statistical and dynamical uncertainty $\left[\forall(\right.$ seas, $\left.k) \widehat{\mathrm{UHI}}_{\text {seas }, k(d)}\left(x_{\text {stat }}\right)=\mathrm{UHI}^{\mathrm{sim}}\left(x_{\mathrm{stat}}, d_{k}^{c}\right)\right]$.

\section{4) OTHER UNCERTAINTIES}

There exist a variety of uncertainties not covered by the previously discussed statistical and dynamical uncertainty.

- In areas with strongly heterogeneous topography (e.g., mountains, islands), it may not be possible to obtain observation or reanalysis data representative for the rural surroundings of the city. Routine observation stations may be unrepresentative (e.g., when separated from the city by mountains) or unavailable (e.g., a city on a small island). Analysis or reanalysis data are available globally, but for heterogeneous topography their resolution may be too coarse to provide forcing data representative for the rural areas close to the city.

- Elevation differences within the urban area are challenging for the proposed SDD. The UI that is superposed to the rural forcing is calculated as the difference between the "urban" and the "nourban" simulations, which have the same relief. An additional height correction can be added to construct the forcing for the long-term offline simulations.

- The use of daily time segments of the simulated UI leads to jumps at the transition between days. A smoothing in time can be applied to reduce these jumps.

- The SDD could be applied to future climate conditions. In this case, it would be necessary to verify that climate change can be represented by the pure change in the frequency of the LWT. This might be the case for LWT that are relatively independent of the absolute value of air temperature, such as those used in the present study. Otherwise, new LWT could appear. Then, the clustering has to be repeated for the future climate period. Furthermore, crucial parameters like sea surface temperature or soil moisture could be different between the historical and future climate. This can be considered by repeating the short-term mesoscale model integrations for future climate conditions.

\section{Observation data and numerical model simulations}

The statistical and dynamical uncertainty of the proposed SDD as defined in section 2 is evaluated for the two midlatitude French cities Toulouse and Dijon.

\section{a. Regional climate and local weather types}

Toulouse (Dijon) is the fourth (17th) largest urban area in France with around 466000 (153000) inhabitants in the main municipality. Toulouse is located in a plain in the southwest of France, $80 \mathrm{~km}$ north of the Pyrenees mountain chain. Its climate consists of mild wet winters and dry hot summers (Joly et al. 2010). The domestic heating period extends from the end of October to midMay (Pigeon et al. 2007). Dijon is located in eastern France, at the interface between the Saône plain in the east and the Morvan low mountain range in the west. It experiences a semicontinental climate with warm summers but a relatively high number of frost days in winter.

The average values of the meteorological parameters for each LWT and the seasonal frequencies of the LWT are shown in the Tables 1 and 2 (Tables 3 and 4) for Toulouse (Dijon). The LWT are shaped by the regional climate and topography of the two cities. In Toulouse, the west-east-oriented Pyrenees mountain chain leads to a high frequency of LWT with westerly and easterly wind direction. In Dijon, the south-north-oriented Morvan low mountain range leads to a high frequency of LWT with southerly and northerly wind direction. 
TABLE 1. Average values of the meteorological parameters per local weather type (LWT) for Toulouse (1 Mar 2004-28 Feb 2005). For the wind direction, quadrant 1 denotes $0^{\circ}-90^{\circ}$, quadrant 2 denotes $90^{\circ}-180^{\circ}$, quadrant 3 denotes $180^{\circ}-270^{\circ}$, and quadrant 4 denotes $270^{\circ}-360^{\circ}$. Degrees are from north, clockwise.

\begin{tabular}{|c|c|c|c|c|c|c|}
\hline LWT $(k)$ & $\Delta T(\mathrm{~K})$ & $\mathrm{RR}\left(\mathrm{mm}\right.$ day $\left.^{-1}\right)$ & $\bar{Q}\left(\mathrm{~g} \mathrm{~kg}^{-1}\right)$ & $\overline{\mathrm{FF}}\left(\mathrm{m} \mathrm{s}^{-1}\right)$ & $\overline{\mathrm{DD}}$ (quad. ) & $f_{k}$ \\
\hline 1 & 5.81 & 6.7 & 6.8 & 2.2 & 4 & 0.05 \\
\hline 2 & 8.84 & 1.0 & 7.4 & 0.7 & 2 & 0.04 \\
\hline 3 & 5.65 & 2.3 & 5.6 & 2.0 & 3 & 0.13 \\
\hline 4 & 12.5 & 0.5 & 5.8 & 1.3 & 4 & 0.04 \\
\hline 5 & 14.6 & 0.2 & 9.2 & 2.2 & 1 & 0.07 \\
\hline 6 & 4.8 & 1.2 & 4.3 & 6.1 & 3 & 0.12 \\
\hline 7 & 7.6 & 2.0 & 6.6 & 4.8 & 3 & 0.15 \\
\hline 8 & 9.8 & 1.0 & 5.7 & 3.1 & 1 & 0.12 \\
\hline 9 & 9.1 & 2.4 & 11.9 & 5.2 & 1 & 0.08 \\
\hline 10 & 13.0 & 0.9 & 8.0 & 2.1 & 3 & 0.08 \\
\hline 11 & 8.3 & 2.0 & 10.7 & 2.8 & 3 & 0.12 \\
\hline
\end{tabular}

The frequencies of the LWT differ as a function of the season, because the LWT with the highest (lowest) daily temperature amplitude do not occur during the winter (summer) season. All LWT occur during the transition seasons.

\section{b. Urban meteorological observations and building energy consumption data}

For Toulouse, observed data are available from the Canopy and Aerosol Particles Interactions in Toulouse Urban Layer (CAPITOUL) campaign (Masson et al. 2008) between March 2004 and February 2005. This exact time period is simulated with the numerical models. A ministation network consisting of 21 stations mounted on electrical towers at the border of the roads was deployed in various districts representative of the urban area. It measured air temperature and relative humidity every $12 \mathrm{~min}$ at $6 \mathrm{~m}$ above ground. A second station network measured air temperature and relative humidity at $2 \mathrm{~m}$ above ground and wind speed and direction at $10 \mathrm{~m}$ above ground at locations representative for the synoptic-scale conditions. Furthermore, a pneumatic tower was mounted on top of the roof of a 20-m-high building in the city center. Tower measurements were conducted at $27.5 \mathrm{~m}$ above the roof for small and moderate wind speed $\left(\mathrm{FF}<70 \mathrm{~km} \mathrm{~h}^{-1}\right)$, and lower height for higher wind speed. At this tower, all meteorological parameters required to force an urban canopy model were measured. The position of the stations with respect to the topography of Toulouse is displayed in Figs. 2c and 2e (metadata are provided in Table S1 in the online supplemental material).

An inventory of building energy consumption has been compiled by Pigeon et al. (2007) for the time period March 2004 to February 2005 based on the real deliveries of natural gas and electricity provided by the energy providers. The electricity consumption is available every
10 min at the urban district scale, and the natural gas consumption is available each day at the scale of the whole urban agglomeration. The spatial disaggregation of the energy consumption data has been made by taking into account the prevailing heating system type and the building surface fraction to obtain a gridded dataset $(100 \mathrm{~m}$ resolution) of daily building energy consumption values for a $15 \mathrm{~km} \times 15 \mathrm{~km}$ domain centered over Toulouse.

For Dijon, observed data are available from a network of 60 stations named Measuring Urban Systems Temperature of Air Round Dijon (MUSTARDijon; Richard et al. 2018) since June 2014 (Figs. 2d,f). It measures air temperature and relative humidity at $3 \mathrm{~m}$ above ground every $30 \mathrm{~min}$. In this study, the period from June 2014 to December 2016 is investigated. No building energy consumption data are available for Dijon; the simulated values will therefore not be evaluated in the present study.

\section{c. UHI definition}

For Toulouse (Dijon), the near-surface air temperature values observed at the stations $7 ; 12 ; 21(1 ; 2 ; 6)$ and

TABLE 2. Frequencies of local weather types (LWT) for the seasons December-February (DJF), March-May (MAM), JuneAugust (JJA), and September-November (SON) for Toulouse (1 Mar 2004-28 Feb 2005).

\begin{tabular}{ccccc}
\hline \hline LWT $(k)$ & $f_{k}^{\text {DJF }}$ & $f_{k}^{\text {MAM }}$ & $f_{k}^{\text {JJA }}$ & $f_{k}^{\text {SON }}$ \\
\hline 1 & 0.06 & 0.05 & 0.01 & 0.09 \\
2 & 0.04 & 0.02 & 0.05 & 0.06 \\
3 & 0.19 & 0.21 & 0.01 & 0.13 \\
4 & 0.06 & 0.04 & 0.01 & 0.06 \\
5 & 0.00 & 0.05 & 0.13 & 0.10 \\
6 & 0.32 & 0.10 & 0.00 & 0.04 \\
7 & 0.09 & 0.22 & 0.15 & 0.13 \\
8 & 0.23 & 0.15 & 0.00 & 0.08 \\
9 & 0.00 & 0.01 & 0.13 & 0.17 \\
10 & 0.01 & 0.13 & 0.13 & 0.03 \\
11 & 0.00 & 0.02 & 0.38 & 0.11 \\
\hline
\end{tabular}


TABLE 3. As in Table 1, but for Dijon (1 Jun 2014-31 Dec 2016).

\begin{tabular}{cccccc}
\hline \hline LWT $(k)$ & $\Delta T(\mathrm{~K})$ & $\mathrm{RR}\left(\mathrm{mm} \mathrm{day}^{-1}\right)$ & $\bar{Q}\left(\mathrm{~g} \mathrm{~kg}^{-1}\right)$ & $\overline{\mathrm{FF}}\left(\mathrm{m} \mathrm{s}^{-1}\right)$ & $\overline{\mathrm{DD}}(\mathrm{quad})$. \\
\hline 1 & 6.3 & 1.1 & 4.4 & 2.6 & 3 \\
2 & 7.5 & 3.8 & 6.7 & 1.5 & 0.08 \\
3 & 6.1 & 2.1 & 5.3 & 3.2 & 4 \\
4 & 14.0 & 0.2 & 8.7 & 1.4 & 0.09 \\
5 & 12.3 & 0.6 & 7.0 & 1.6 & 0.14 \\
6 & 12.1 & 0.9 & 8.1 & 1.7 & 0.08 \\
7 & 16.0 & 1.0 & 9.6 & 2.2 & 4 \\
8 & 7.3 & 3.4 & 9.4 & 2.5 & 0.10 \\
9 & 6.5 & 10.0 & 9.5 & 4.2 & 0.13 \\
10 & 10.1 & 0.0 & 5.4 & 1.4 & 0.05 \\
11 & 4.5 & 2.1 & 5.6 & 0.08 \\
\hline
\end{tabular}

$22 ; 24 ; 27(33 ; 34 ; 35 ; 36 ; 38)$ are taken as representative for the dense urban and rural environment, respectively. The time series of the observed UHI [UHI $\left.{ }^{\mathrm{obs}}\left(x_{\mathrm{urb}}, d\right)\right]$ is then defined as the difference between the near-surface air temperature in the dense urban and the rural environment.

Stewart (2011) defined nine scientific criteria to evaluate the quality of UHI studies. Some of these cannot be fully met in the present study. Elevation differences between the urban and rural stations can influence the UHI intensity. For Dijon, the rural stations located in the low mountain range are therefore not taken into account. The selected rural stations are on average $18 \mathrm{~m}$ lower than the selected urban stations; their elevation difference should only slightly influence the results. For Toulouse, rural station 24 is located $70 \mathrm{~m}$ higher than the urban stations. This elevation difference may influence the results slightly. However, no elevation correction is made, as it is not clear which lapse rate should be applied. Particularly at the night, when the UHI is largest, there may be inversions, and thus the correction using a dry adiabatic or a standard atmosphere lapse rate would worsen the quality of the data. A further shortcoming of the UHI definition for Toulouse is the fact that, while the rural stations measure at $2 \mathrm{~m}$ above the ground, the urban stations measure at $6 \mathrm{~m}$ above the ground. During the CAPITOUL campaign, the sensitivity to measurement height ( $6 \mathrm{~m}$ vs $2 \mathrm{~m}$ ) has been tested for one urban station; results showed that the influence was small. In summary, the UHI definition for Dijon is more robust than for Toulouse, since there are fewer elevation differences between the urban and rural stations and the variables of interest are measured at the same height above ground.

\section{d. Numerical simulations}

To evaluate the SDD, long-term numerical simulations are performed using the mesoscale atmospheric model Meso-NH (Lafore et al. 1998; Lac et al. 2018). It is used to dynamically downscale the European Centre for Medium-Range Weather Forecasts (ECMWF) Integrated Forecasting System high-resolution operational forecast analyses. Their horizontal resolution is about $40 \mathrm{~km}$ in 2004-05, $16 \mathrm{~km}$ from 26 January 2010 to 7 March 2016, and about $9 \mathrm{~km}$ since 8 March 2016 (https://www.ecmwf.int/en/ forecasts/documentation-and-support/changes-ecmwfmodel). The analysis data are downscaled via three intermediate nesting steps to a horizontal resolution of $250 \mathrm{~m}$. The horizontal grid resolutions of the four domains are $8 \mathrm{~km}$ (D1), $2 \mathrm{~km}$ (D2), $1 \mathrm{~km}$ (D3), and $250 \mathrm{~m}$ (D4). Table 5 summarizes the employed physical parameterizations; the delimitation of the model domains is displayed in Figs. 2a and 2b. For more details on the model configuration, the reader is referred to section 3 of Kwok et al. (2019).

Meso-NH is coupled with Surface Externalisée (SURFEX; Masson et al. 2013) to solve the surface energy budget. SURFEX employs the urban canopy model Town Energy Balance (TEB; Masson 2000) for urban areas and the soilvegetation-atmosphere-transfer model ISBA (Noilhan and Planton 1989) for rural areas. TEB assumes a simple urban geometry with buildings aligned along street canyons and solves the surface energy budget separately for a representative roof, wall, and road. In-canyon urban

TABLE 4. As in Table 2, but for Dijon (1 Jun 2014-31 Dec 2016).

\begin{tabular}{ccccc}
\hline \hline LWT $(k)$ & $f_{k}^{\text {DJF }}$ & $f_{k}^{\text {MAM }}$ & $f_{k}^{\text {JJA }}$ & $f_{k}^{\text {SON }}$ \\
\hline 1 & 0.16 & 0.14 & 0.00 & 0.06 \\
2 & 0.16 & 0.09 & 0.02 & 0.11 \\
3 & 0.36 & 0.14 & 0.01 & 0.09 \\
4 & 0.01 & 0.05 & 0.16 & 0.07 \\
5 & 0.04 & 0.12 & 0.15 & 0.08 \\
6 & 0.05 & 0.11 & 0.20 & 0.13 \\
7 & 0.00 & 0.05 & 0.11 & 0.04 \\
8 & 0.00 & 0.03 & 0.19 & 0.06 \\
9 & 0.01 & 0.08 & 0.11 & 0.07 \\
10 & 0.06 & 0.16 & 0.05 & 0.16 \\
11 & 0.15 & 0.03 & 0.00 & 0.13 \\
\hline
\end{tabular}


Toulouse

(a)

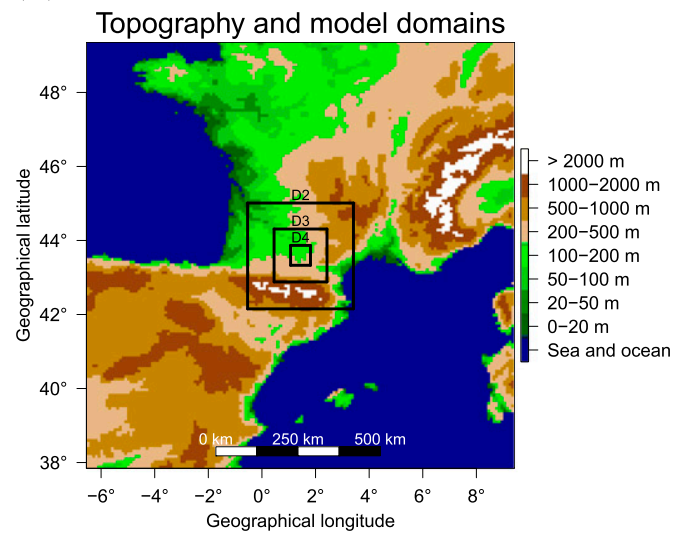

(c)

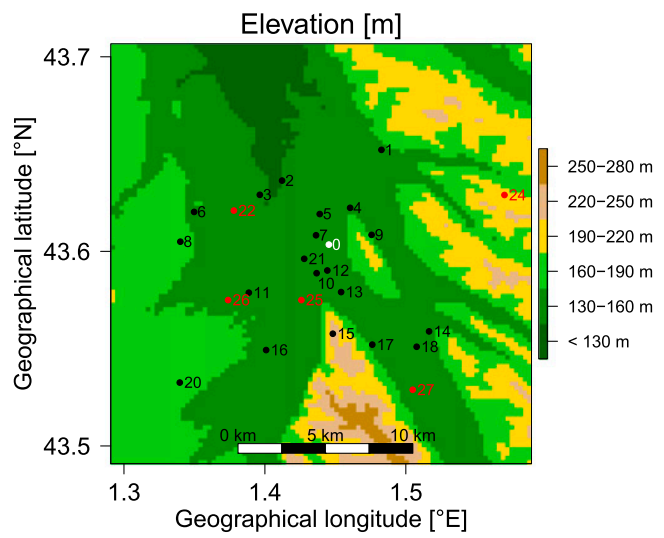

(e)

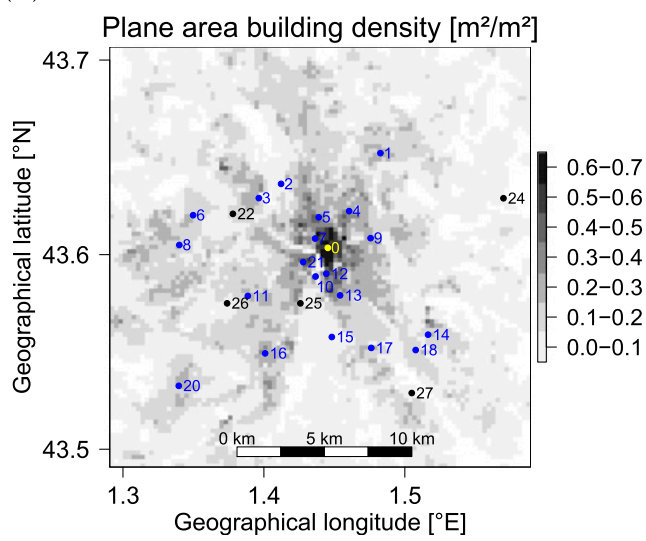

Dijon

(b)

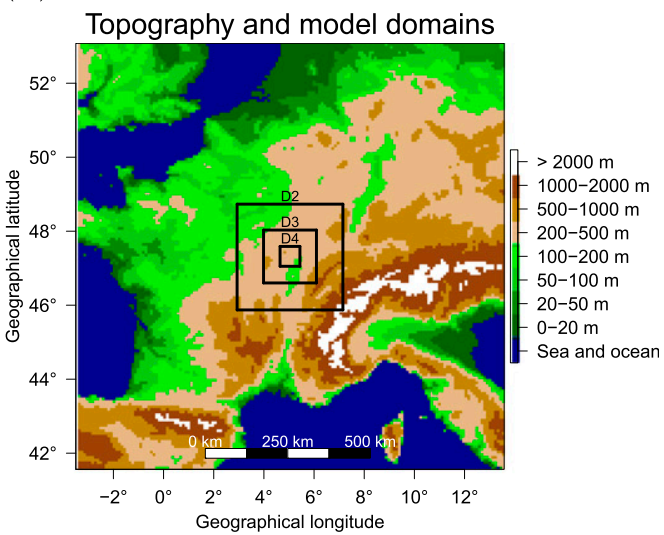

(d)

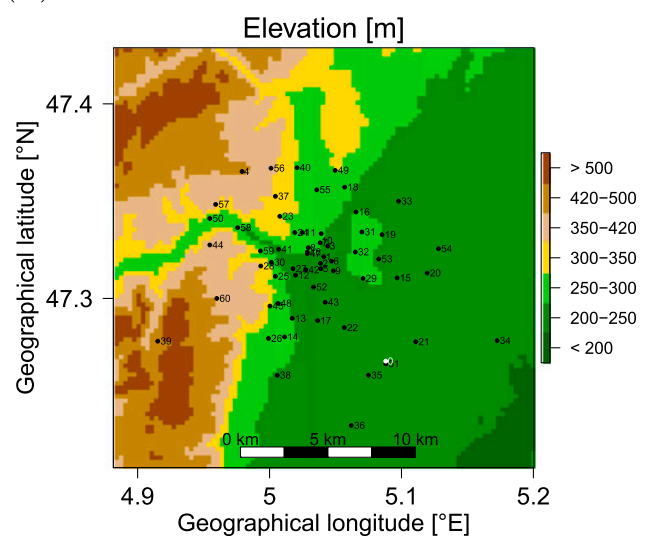

(f)

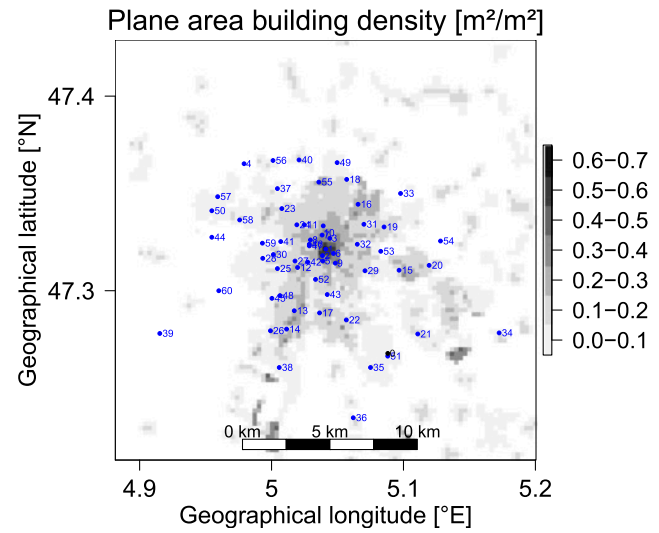

FIG. 2. (a),(b) Overview of the model domains and topography. (c),(d) Location of the stations with respect to elevation and (e),(f) plane area building density. Station metadata are given in the Tables S1 and S2. In the middle row, for Toulouse, white depicts the tower, black the urban station network, and red the synoptic station network. For Dijon, white depicts the synoptic station Longvic airport and black the urban station network. 
TABLE 5. Physical parameterizations employed for the Meso-NH simulations.

\begin{tabular}{ccclcl}
\hline \hline Domain & $\begin{array}{c}\text { Horizontal } \\
\text { resolution }(\mathrm{km})\end{array}$ & $\begin{array}{c}\text { Time } \\
\text { step }(\mathrm{s})\end{array}$ & $\begin{array}{c}\text { Parameterization of } \\
\text { deep convection }\end{array}$ & $\begin{array}{c}\text { Parameterization of shallow } \\
\text { convection and dry thermals }\end{array}$ & Mixing length calculation \\
\hline D1 & 8 & 15 & Kain and Fritsch (1990) & Pergaud et al. (2009) & Bougeault and Lacarrère (1989) \\
D2 & 2 & 15 & None & Pergaud et al. (2009) & Bougeault and Lacarrère (1989) \\
D3 & 1 & 15 & None & None & Bougeault and Lacarrère (1989) \\
D4 & 0.25 & 7.5 & None & None & Deardorff (1980) \\
\hline
\end{tabular}

vegetation is taken into account with the approach of Lemonsu et al. (2012). A building energy module (Bueno et al. 2012; Pigeon et al. 2014) solves the energy budget of a representative building at district scale. Vertical profiles of meteorological parameters in the street canyon are calculated using the surface boundary layer (SBL) scheme of Hamdi and Masson (2008). A similar SBL scheme is employed in rural areas. Data on the urban form and function of Toulouse and Dijon are taken from the MApUCE database (http:// mapuce.orbisgis.org/). These data deal with urban morphology (Bocher et al. 2018), construction materials and their physical properties (Tornay et al. 2017), human behavior related to building energy consumption (Schoetter et al. 2017), and urban vegetation (Crombette et al. 2014). The center of Toulouse (Dijon) is characterized by historical red brick (limestone) buildings with roofs mainly covered with tiles. The land-cover parameters for the rural areas are taken from the $1 \mathrm{~km}$ resolution Ecosystem Climate Map (ECOCLIMAP-I) database (Masson et al. 2003; Champeaux et al. 2005).

Only the model output for D4 is analyzed. The model output from the vertical level of the SBL scheme closest to the height of the station observation is taken. For the stations measuring at 2 or $3 \mathrm{~m}$ above the ground, this is exactly $2 \mathrm{~m}$; for the stations measuring $6 \mathrm{~m}$ above ground, the corresponding SBL level is at about $5 \mathrm{~m}$ above ground. The average of the model output for all grid points within a distance of less than $250 \mathrm{~m}$ to the station (2-4 grid points) is calculated.

Evaluation of building energy consumption simulated by the coupled Meso-NH-TEB and the TEB offline is restricted to Toulouse, since an inventory of building energy consumption is available only for this city. The total building energy consumption is the sum of the energy consumption due to electrical appliances, lighting, cooking, and heating of buildings. The building energy consumption due to electrical appliances, lighting and cooking is specified as a function of building use, household characteristics, and sociodemographical factors based on surveys of energy use in France (Bourgeois et al. 2017). The building energy consumption due to heating of buildings is simulated by the building energy model included in TEB as a function of the prevailing meteorological conditions, the characteristics of the building envelope (available from Tornay et al. 2017), the type of the heating system, and the heating setpoint temperature. The heating setpoint temperature is specified as a function of building use, the type of the heating system, and sociodemographical factors as described in Bourgeois et al. (2017) and Schoetter et al. (2017). Air conditioning was not a relevant contribution to building energy consumption in Toulouse during summer 2004.

The SURFEX offline simulations are forced by the meteorological parameters observed at the tower at about $20 \mathrm{~m}$ above the average building height. The air temperature observed at the tower $\left(T_{\mathrm{tow}}^{\mathrm{obs}}\right)$ placed in the city center represents the conditions in the urban environment at the position of the tower $\left(x_{\text {tow }}\right)$. During a practical application of the SDD, high-quality observations from routine meteorological stations are usually not available in the city center since these stations are placed at sites representative for the synoptic-scale meteorological conditions outside the city center (e.g., airports). To take into account the uncertainty due to the use of observations from a location outside the urban area, the air temperature at forcing height corrected for the urban influence at the position of the Blagnac airport station $\left[x_{\text {apt }}\right.$; number 22 in Figs. $2 c$ and 2e; Eq. (18)] is calculated. The forcing data for SURFEX containing the spatial pattern of the UI are then calculated following Eq. (19):

$$
\begin{aligned}
T_{\text {rur }}\left(x_{\mathrm{apt}}, d\right)= & T_{\mathrm{tow}}^{\mathrm{obs}}\left(x_{\mathrm{tow}}, d\right)-\left[T_{\mathrm{urb}}^{\mathrm{sim}}\left(x_{\mathrm{tow}}, d\right)\right. \\
& \left.-T_{\mathrm{nourb}}^{\mathrm{sim}}\left(x_{\mathrm{apt}}, d\right)\right], \quad \text { and } \\
\forall(\operatorname{seas}, k) T_{\mathrm{urb}}(x, d)= & T_{\mathrm{rur}}\left(x_{\mathrm{apt}}, d\right)+\widehat{\mathrm{UI}}_{\mathrm{seas}, k(d)}^{\mathrm{sim}}(x),
\end{aligned}
$$

\section{Results}

\section{a. Model performance at synoptic stations}

The hourly values of meteorological parameters are evaluated at the synoptic stations Météopole (number 26 in Figs. 2c and 2e) and Longvic airport (number 0 in Figs. 2d and 2f) for Toulouse and Dijon, respectively. Evaluation measures are provided in Tables 6 and 7. 
TABLE 6. Evaluation measures calculated based on hourly values of meteorological parameters simulated by Meso-NH at the synoptic station Météopole (No. 26, Fig. 2c) in Toulouse. The desired accuracy for the calculation of the hit rate is $2 \mathrm{~K}$ for air temperature, $14 \%$ for specific humidity, $1 \mathrm{~m} \mathrm{~s}^{-1}$ for wind speed, and $30^{\circ}$ for wind direction.

\begin{tabular}{|c|c|c|c|c|}
\hline & DJF & MAM & JJA & SON \\
\hline \multicolumn{5}{|c|}{ Air temperature, $2 \mathrm{~m}$} \\
\hline Bias $(\mathrm{K})$ & -0.3 & 0.2 & 3.1 & -0.2 \\
\hline Rmse (K) & 1.9 & 1.7 & 3.8 & 1.9 \\
\hline Hit rate & 0.73 & 0.78 & 0.33 & 0.74 \\
\hline \multicolumn{5}{|c|}{ Specific humidity, $2 \mathrm{~m}$} \\
\hline $\operatorname{Bias}\left(\mathrm{g} \mathrm{kg}^{-1}\right)$ & -0.1 & 0.3 & -0.2 & 0.0 \\
\hline $\operatorname{Rmse}\left(\mathrm{g} \mathrm{kg}^{-1}\right)$ & 0.5 & 0.8 & 1.3 & 0.9 \\
\hline Hit rate & 0.80 & 0.75 & 0.73 & 0.79 \\
\hline \multicolumn{5}{|c|}{ Total downwelling solar radiation } \\
\hline $\operatorname{Bias}\left(\mathrm{W} \mathrm{m}^{-2}\right)$ & 1.2 & 23.1 & 57.7 & 5.1 \\
\hline \multicolumn{5}{|c|}{ Wind speed, $10 \mathrm{~m}$} \\
\hline $\operatorname{Bias}\left(\mathrm{m} \mathrm{s}^{-1}\right)$ & 0.4 & 0.3 & 0.7 & 0.4 \\
\hline Rmse $\left(\mathrm{m} \mathrm{s}^{-1}\right)$ & 1.4 & 1.4 & 1.6 & 1.3 \\
\hline Hit rate & 0.55 & 0.59 & 0.50 & 0.62 \\
\hline \multicolumn{5}{|c|}{ Wind direction, $10 \mathrm{~m}$} \\
\hline Rmse $\left(^{\circ}\right)$ & 59.2 & 59.5 & 67.9 & 68.4 \\
\hline Hit rate & 0.64 & 0.60 & 0.56 & 0.56 \\
\hline
\end{tabular}

In general, the model performance is acceptable, given that Meso-NH is forced only at the lateral boundaries and no data assimilation takes place. A noteworthy model deficiency is the warm bias of $3 \mathrm{~K}$ for JJA in Toulouse. Interestingly, a similar warm bias in JJA is not found in Dijon, which is probably due to the different regional climate or topography. Downwelling solar radiation at the surface is overestimated for both cities and all seasons. Wind speed and direction are simulated well for both cities. In summary, model evaluation reveals two main issues: the warm bias for JJA in Toulouse and the general overestimation of downwelling shortwave radiation. The investigation of the physical mechanisms related to these biases is beyond the scope of the present study.

\section{b. Statistical uncertainty}

The evaluation measures defined in section 2 to quantify the statistical uncertainty of the SDD are displayed in Fig. 3 (Fig. 4) for Toulouse (Dijon). In this section, both the results for UI at $2 \mathrm{~m}$ above ground (UI2M), relevant for the screen-level conditions, and UI at $10 \mathrm{~m}$ above the urban canopy layer (UI10M), relevant for the reconstruction of the forcing for the SURFEX offline simulations, are discussed. The bias (Fig. 4, top line) and rmse (Fig. 4, middle line) are shown as an example for the grid point covering station 12 (1) for Toulouse (Dijon), which is
TABLE 7. As in Table 6, but for the station at Dijon Longvic airport (No. 0 in Fig. 2d).

\begin{tabular}{|c|c|c|c|c|}
\hline & DJF & MAM & JJA & SON \\
\hline \multicolumn{5}{|c|}{ Air temperature, $2 \mathrm{~m}$} \\
\hline Bias $(\mathrm{K})$ & -0.1 & -0.5 & -0.3 & -1.1 \\
\hline Rmse (K) & 2.0 & 1.8 & 2.3 & 2.2 \\
\hline Hit rate & 0.72 & 0.76 & 0.62 & 0.62 \\
\hline \multicolumn{5}{|c|}{ Specific humidity, $2 \mathrm{~m}$} \\
\hline $\operatorname{Bias}\left(\mathrm{g} \mathrm{kg}^{-1}\right)$ & 0.0 & 0.5 & 0.2 & -0.1 \\
\hline $\operatorname{Rmse}\left(\mathrm{g} \mathrm{kg}^{-1}\right)$ & 0.6 & 1.0 & 1.3 & 0.9 \\
\hline Hit rate & 0.77 & 0.66 & 0.73 & 0.79 \\
\hline \multicolumn{5}{|c|}{ Total downwelling solar radiation } \\
\hline $\operatorname{Bias}\left(\mathrm{W} \mathrm{m}^{-2}\right)$ & 7.7 & 12.5 & 26.0 & 1.5 \\
\hline \multicolumn{5}{|c|}{ Wind speed, $10 \mathrm{~m}$} \\
\hline $\operatorname{Bias}\left(\mathrm{m} \mathrm{s}^{-1}\right)$ & 0.3 & 0.0 & 0.2 & 0.1 \\
\hline $\operatorname{Rmse}\left(\mathrm{m} \mathrm{s}^{-1}\right)$ & 1.4 & 1.3 & 1.4 & 1.3 \\
\hline Hit rate & 0.56 & 0.59 & 0.58 & 0.61 \\
\hline \multicolumn{5}{|c|}{ Wind direction, $10 \mathrm{~m}$} \\
\hline Rmse $\left(^{\circ}\right)$ & 69 & 64 & 68 & 69 \\
\hline Hit rate & 0.6 & 0.59 & 0.53 & 0.56 \\
\hline
\end{tabular}

located in the city center. The results for the pattern correlation (paco) (Fig. 4, bottom line) are displayed as an example for the average nocturnal (0200 to 0500 local time) UI in DJF.

NO-UI leads to the worst results for all evaluation measures, and WT-MEAN-UI leads to the best. However, for WT-MEAN-UI rmse $\neq 0$, because the LWT do not explain the entire UI variation. For Toulouse, the ECV [Eq. (10)] at the location of the stations is between $45 \%$ and $65 \%$ for UI $2 \mathrm{M}$ and $35 \%$ and $55 \%$ for UI $10 \mathrm{M}$. The corresponding ranges for Dijon are $20 \%-60 \%$ and $20 \%-55 \%$, and the lowest values of $\mathrm{ECV}$ are found for stations far from the city center. The values obtained for EVC are higher than those reported by Hoffmann and Schluenzen (2013) for synoptic-scale weather patterns and in the same order of magnitude as those obtained by Hoffmann et al. (2018) by the combination of these weather patterns with local meteorological predictors of the UHI. It is also plausible that ECV is lower for UI10M than for UI2M since the further away from the surface, the less the air temperature is directly influenced by the underlying land cover.

The results show that simulating only the centroid day to represent each LWT (WT-CENT-UI) leads to suboptimal values of the rmse and paco. For both cities, the rmse for WT-CENT-UI is larger than for WT-MEAN-UI, which demonstrates that the small-scale intra-LWT variability dominates over the explained UI variation by the LWT. The paco also deviates from its optimum value of 1 , especially for UI10M, which is less constrained by the surface than UI2M. If 3-6 days 
$2 \mathrm{~m}$ above ground (UI2M)

(a)

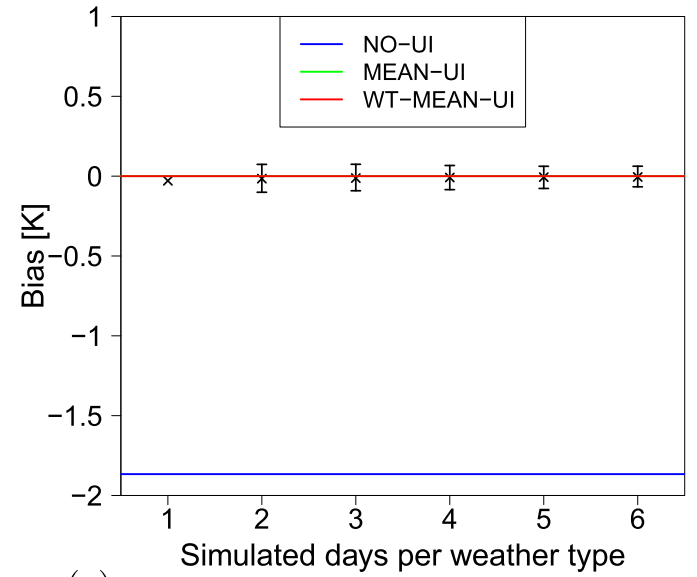

(c)

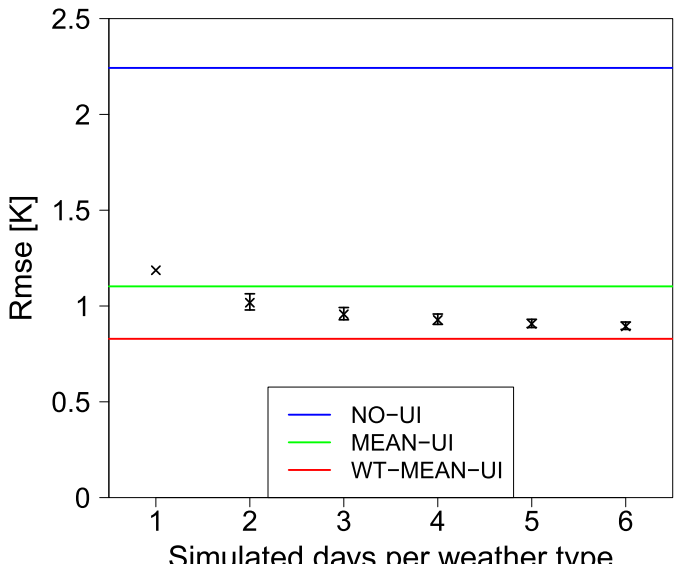

(e)

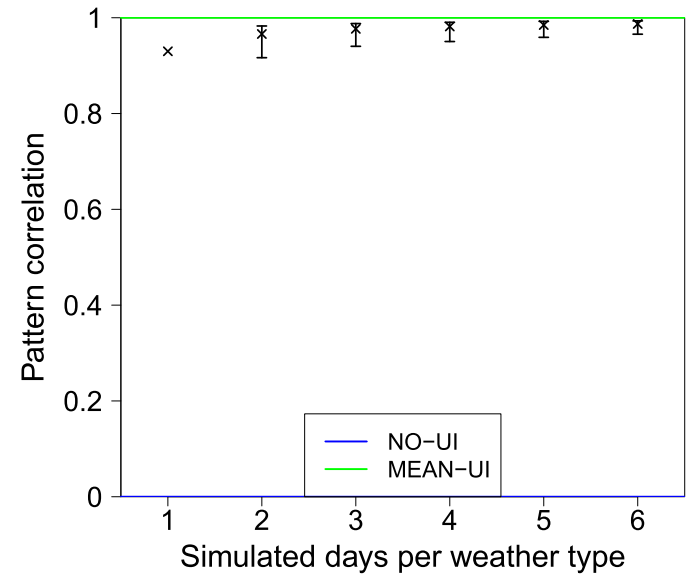

$10 \mathrm{~m}$ above urban canopy (UI10M)

(b)

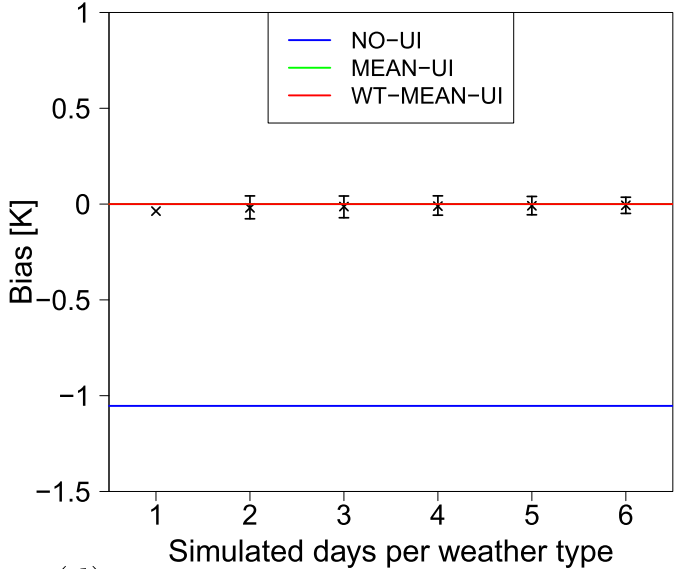

(d)

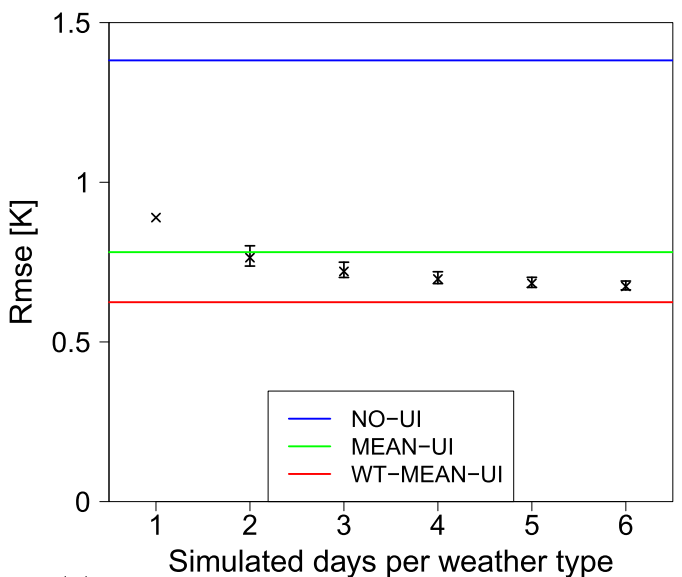

(f)

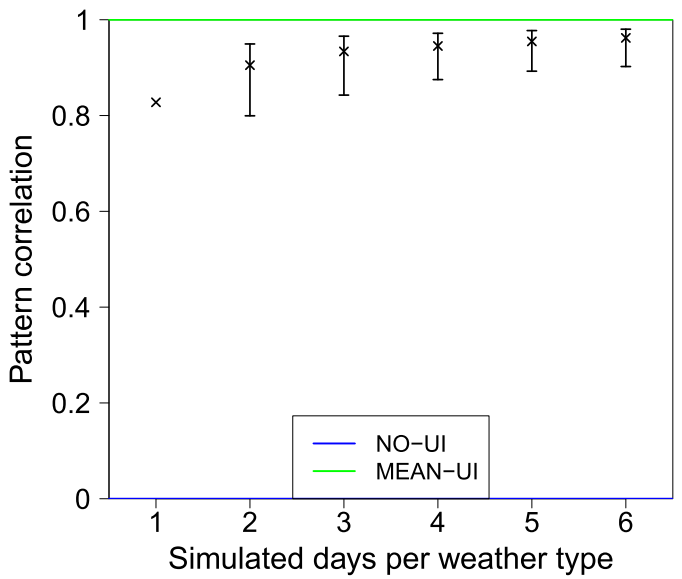

FIG. 3. Evaluation measures for the reconstructed time series of the urban influence on air temperature (UI) for Toulouse. (a),(b) Bias and (c),(d) rmse of the UI time series at the location of station 12 in central Toulouse. (e),(f) Pattern correlation (paco) of the nocturnal (2 to 5 local time) UI for DJF. 1000 Bootstrap resamples have been drawn to estimate the confidence intervals. The cross depicts the median, the confidence intervals the 5 th to 95th percentile of the model evaluation measures. 
$2 \mathrm{~m}$ above ground (UI2M)

(a)

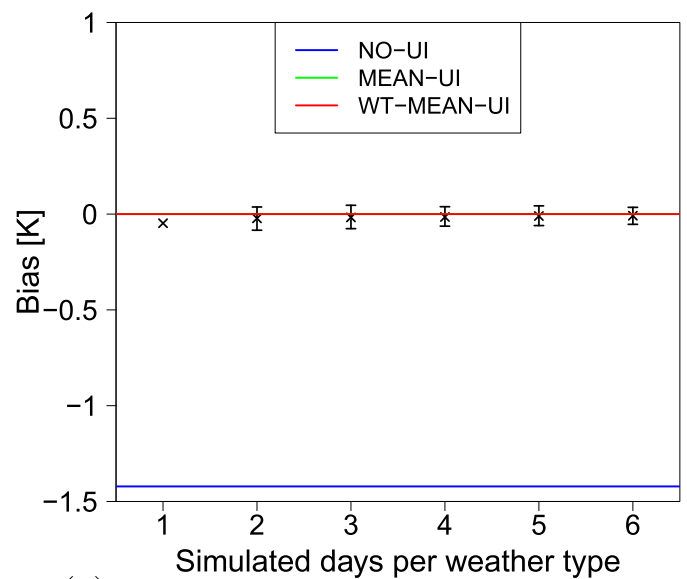

(c)

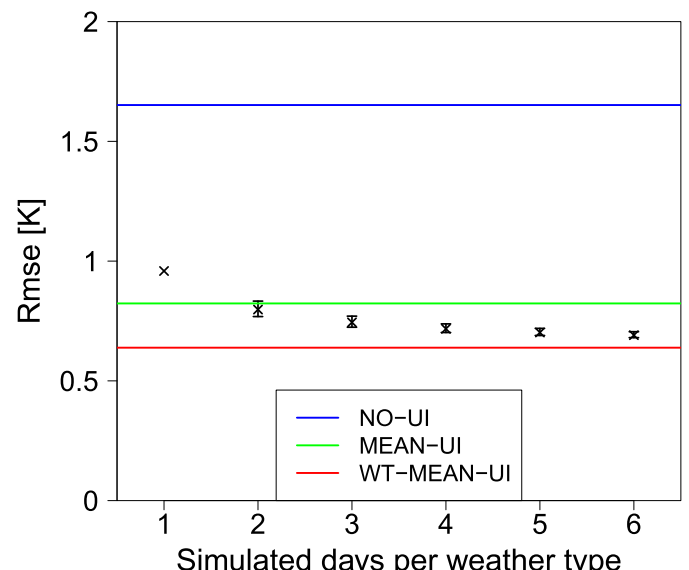

(e)

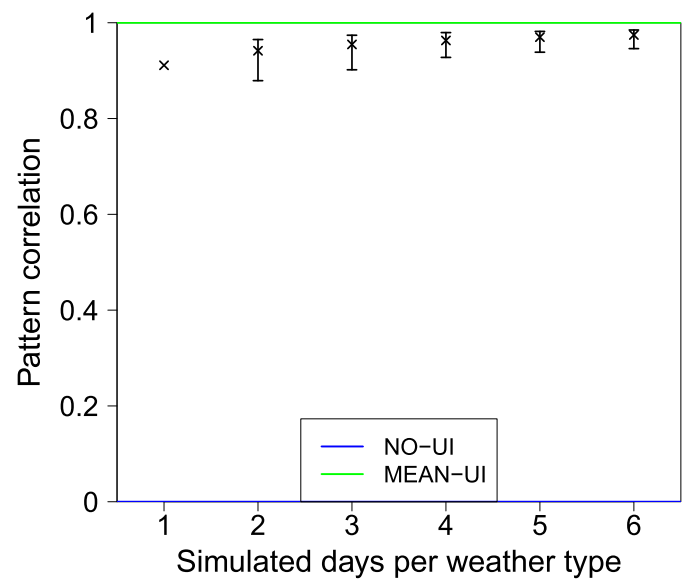

$10 \mathrm{~m}$ above urban canopy (UI10M)

(b)

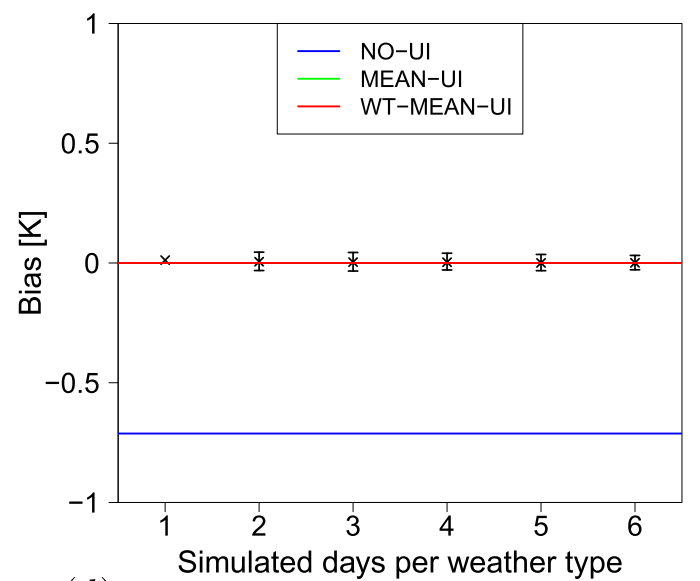

(d)

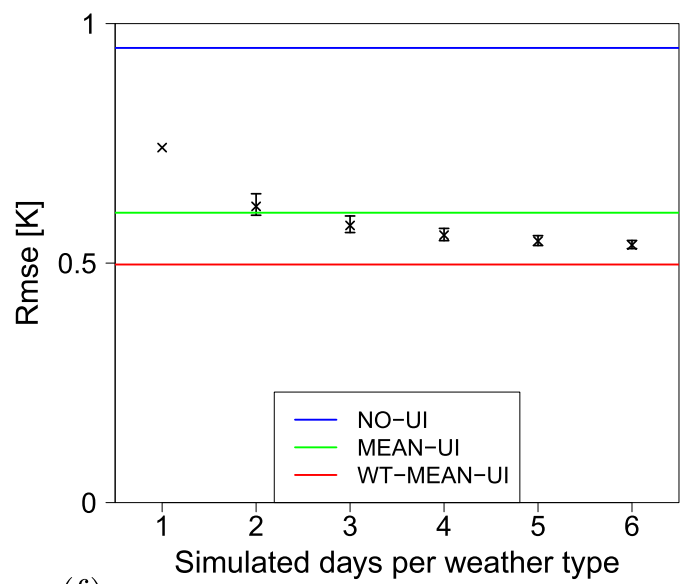

(f)

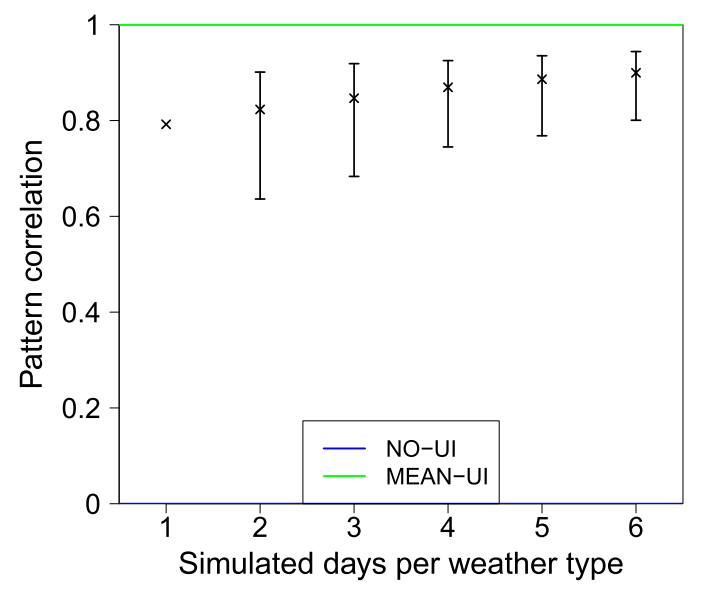

FIG. 4. As in Fig. 3, but for Dijon. 
are simulated for each LWT, the evaluation measures converge toward their optimum values. For Toulouse (Dijon), only 1 (2.5) year is available. Therefore, the days to be considered for each LWT have been selected using the bootstrapping method so as not to artificially reduce the uncertainty by sampling all days. Here, 1000 bootstrap samples are taken from the original by using sampling with replacement to estimate the confidence intervals following Efron (1979).

For other grid points in the urban areas, very similar results are found for the bias and the rmse (not shown). For the paco, the results are generally better for other seasons than those shown for DJF, mainly due to lower advection.

In Fig. 5 (Fig. 6), the seasonal mean nocturnal UI2M patterns are shown for Toulouse (Dijon). The left column displays the results obtained when recombining the UI patterns simulated for the LWT centroid days, the middle column the results obtained when simulating 6 days per LWT. The right column shows the results obtained from the long-term simulation (the reference). For both cities, the average UI2M patterns obtained using the LWT centroid days are not substantially different from the reference, since the urban influence on near-surface air temperature is shaped largely by the local topography. This is consistent with the relatively high values for paco found for WT-CENT-UI. However, there are some shortcomings for WT-CENT-UI. For Toulouse, the UI is too low in JJA and too high in SON, which is considerably improved for WT-6DAY-UI. Similar conclusions can be drawn for UI10M (not shown), although the spatial pattern for WT-6DAY-UI differs more from the reference than for UI2M, which corroborates the results obtained for paco (Figs. 3e,f and 4e,f).

\section{c. Dynamical uncertainty}

The dynamical uncertainty is quantified by evaluating the simulated nocturnal (0200 to 0500 local time) UHI intensity per season and LWT for Toulouse (Fig. 7) and Dijon (Fig. 8). Only those LWT that occur for more than 5 days for each season are analyzed, since Stewart (2011) state that UHI intensities calculated from one or only a few nights lack robustness. Seasonal average UHI intensities are captured for Dijon, with biases of only $0.1-0.2 \mathrm{~K}$. The UHI is lowest in DJF (Fig. 8a), and highest in MAM (Fig. 8b) and JJA (Fig. 8c). Meso-NH captures well these seasonal differences. For Toulouse, the UHI intensity is slightly $(0.3 \mathrm{~K})$ overestimated in DJF (Fig. 7a) and considerably (up to $0.8 \mathrm{~K}$ ) overestimated in the other seasons. This overestimation is found for all LWT.

For both cities and all seasons, the values for the CDCI (Figs. 7 and 8) are larger than 0 . This is an encouraging result, since it demonstrates that, on average, for LWT with a relatively low (high) observed UHI intensity, the simulated UHI intensity tends to be relatively low (high). Meso-NH therefore captures, on average, the relationship between the UHI intensity and the LWT. However, there are single LWT for which the simulated UHI intensities show biases even though the seasonal average UHI intensity is simulated well. In Dijon, this is the case for LWT 6 in DJF (Fig. 8a) and LWT 7 in JJA (Fig. 8c). Both these LWT are characterized by a relatively high daily temperature amplitude and low wind speed. For Toulouse, this is the case for LWT 7, which is characterized by a medium temperature amplitude and a moderate westerly wind. Investigation of the UI for the problematic seasons and LWT reveals that Meso-NH simulates a relatively strong UI for these LWT, not only in the city center, but also in the suburban areas and nearly rural areas where the rural stations are located. As a consequence, the simulated UHI, the difference between the urban and rural stations, is too low for these LWT. A possible reason is that the model grid points taken to represent the rural stations are not completely free of buildings. For Toulouse, the plane area building density is $0,0.05$, and 0.12 for stations 24,27 , and 22 , respectively. For Dijon, the values of the plane area building density for the rural stations are between 0.0 and 0.08 . The grid points of the rural stations might be too heavily influenced by the urbanization for the problematic LWT.

The observed daytime (1300 to 1600 local time) UHI is lower than the nocturnal UHI for all seasons, LWT and the two cities (not shown). This is consistent with knowledge about the UHI effect. For Dijon, the simulated and observed UHI agree, with up to $0.5 \mathrm{~K}$ bias for some LWT. For Toulouse, similar to the nocturnal UHI, larger biases are found. The UHI intensity is overestimated by 0.5 to $1.0 \mathrm{~K}$ in MAM, SON, and DJF, whereas it is underestimated by about $0.5 \mathrm{~K}$ in JJA. These biases are relatively independent of the LWT.

An interesting finding is that the UHI intensity is considerably better simulated for Dijon than for Toulouse. This might be due to the fact that the station observations available to define the UHI are more robust for Dijon, since there are more rural stations available, the elevation differences are lower, and the urban and rural stations measure at the same height.

\section{d. Contributions of statistical and dynamical uncertainty}

The evaluation measures quantifying the contributions of the statistical and the dynamical uncertainty are given in Table 8. Results show that for the bias in Toulouse the dynamical uncertainty dominates. No relevant bias is simulated for Dijon. For the rmse, the statistical and the dynamical uncertainty have about 
(a) DJF, WT-CENT-UI

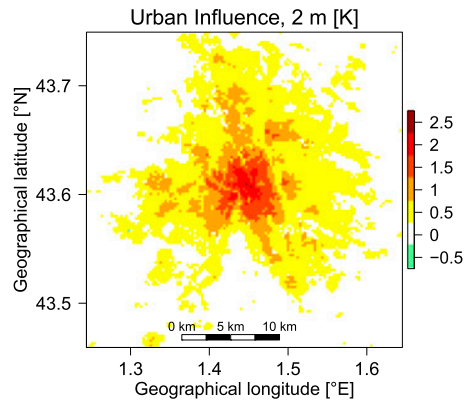

(d) MAM, WT-CENT-UI

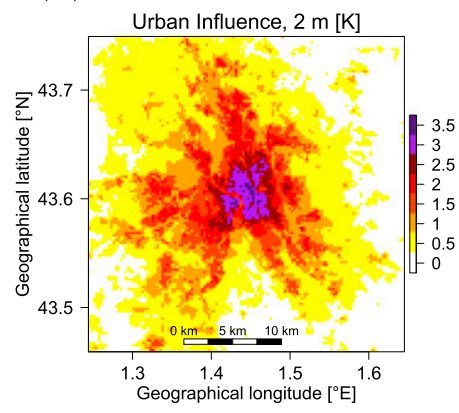

(g) JJA, WT-CENT-UI

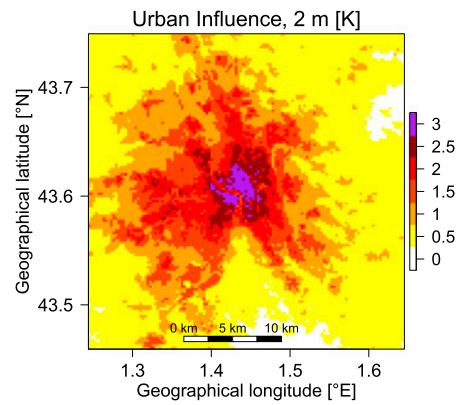

(j) SON, WT-CENT-UI

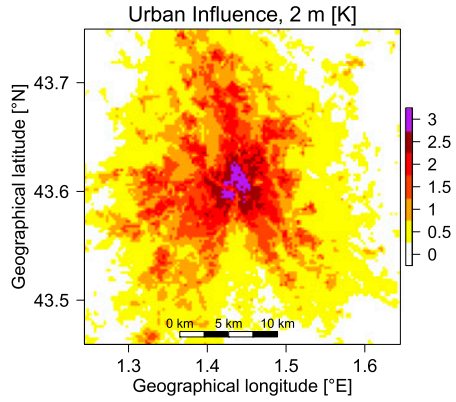

(b) DJF, WT-6DAY-UI

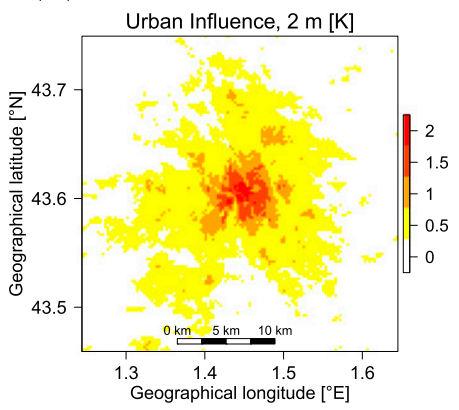

(e) MAM, WT-6DAY-UI

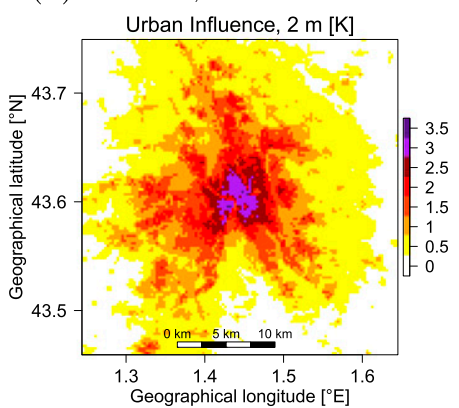

(h) JJA, WT-6DAY-UI

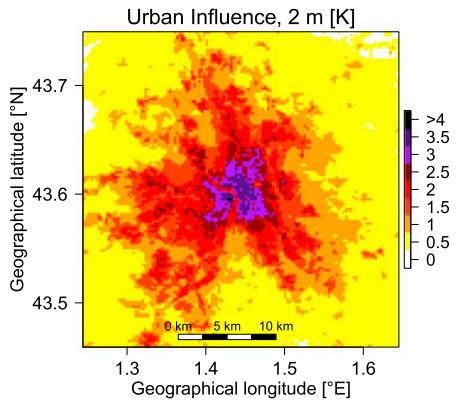

(k) SON, WT-6DAY-UI

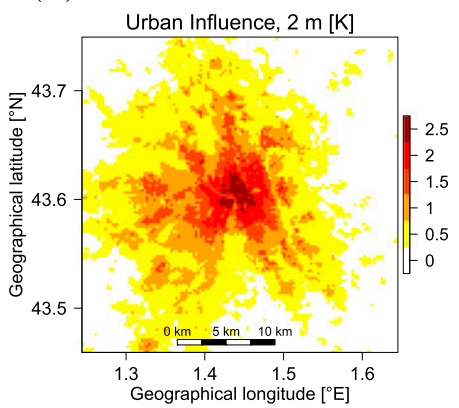

(c) DJF, Reference

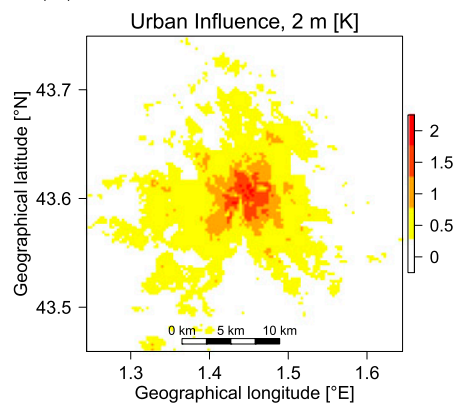

(f) MAM, Reference

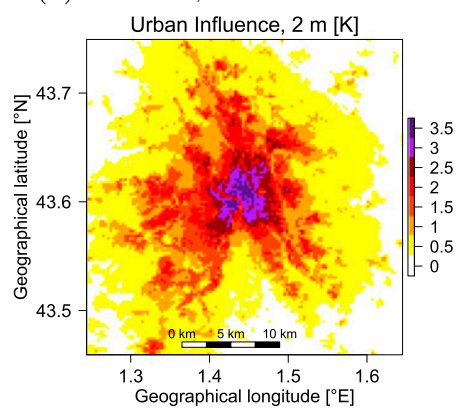

(i) JJA, Reference

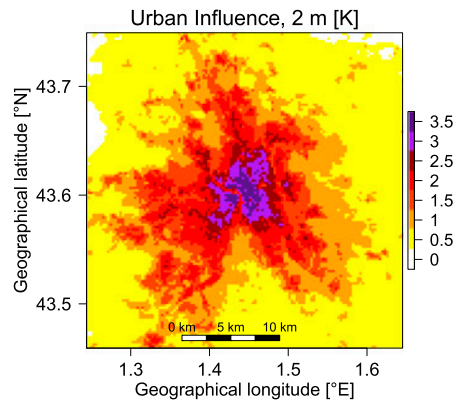

(l) SON, Reference

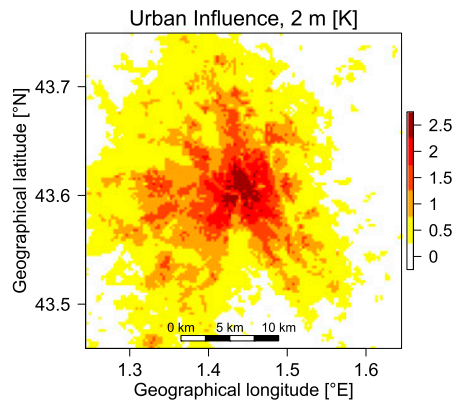

FIG. 5. Seasonal means of nocturnal ( 2 to 5 local time) urban influence on air temperature in $2 \mathrm{~m}$ above ground for Toulouse. (left) Weighted average of the UI patterns simulated for the LWT centroid days (WT-CENT-UI); (middle) as in (left), but when simulating 6 days per LWT (WT-NDAY-UI with $N=6$; WT-6DAY-UI); (right) reference solution from the long-term numerical integration. 
(a) DJF, WT-CENT-UI

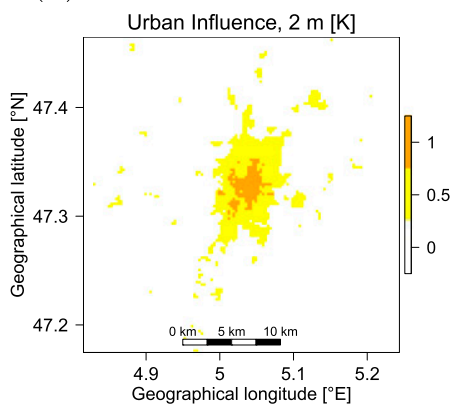

(d) MAM, WT-CENT-UI

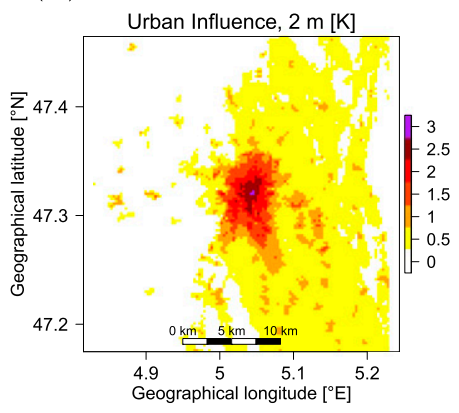

(g) JJA, WT-CENT-UI

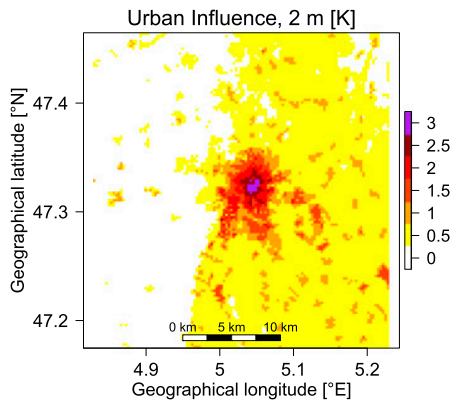

(j) SON, WT-CENT-UI

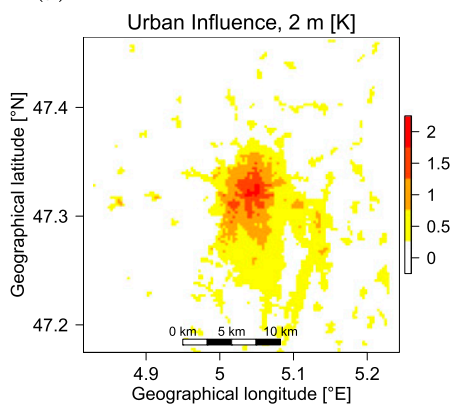

(b) DJF, WT-6DAY-UI

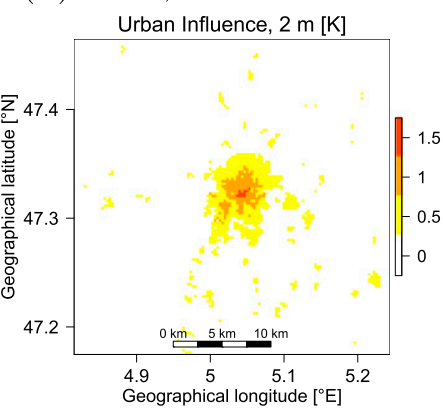

(e) MAM, WT-6DAY-UI

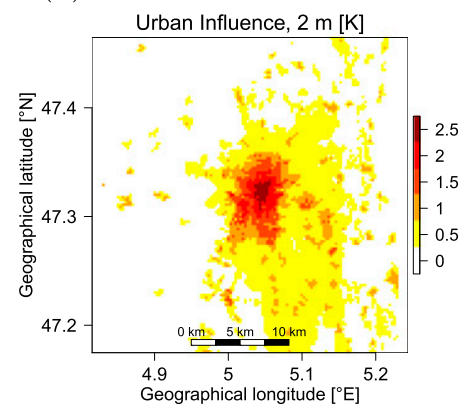

(h) JJA, WT-6DAY-UI

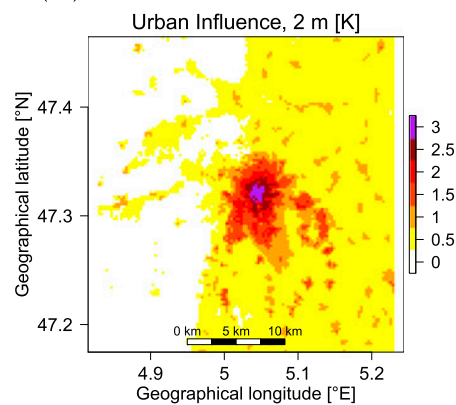

(k) SON, WT-6DAY-UI

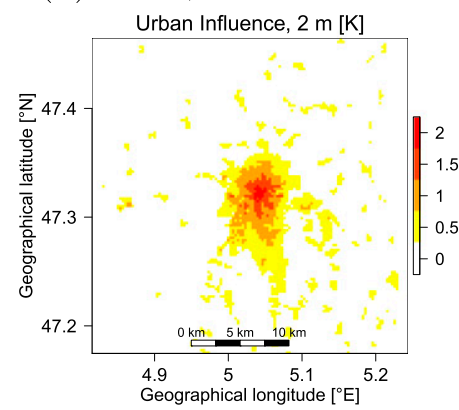

FIG. 6. As in Fig. 5, but for Dijon. (c) DJF, Reference

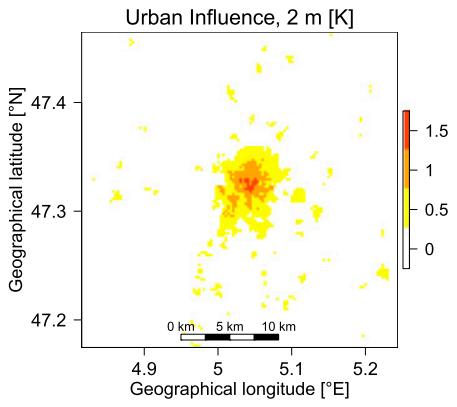

(f) MAM, Reference

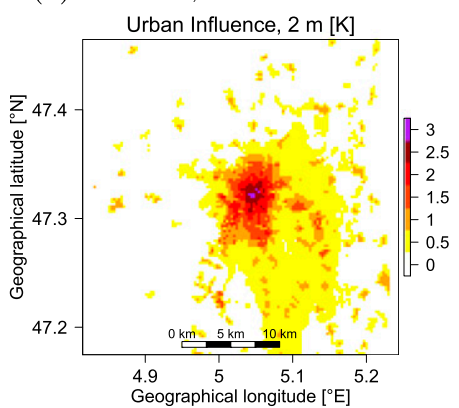

(i) JJA, Reference

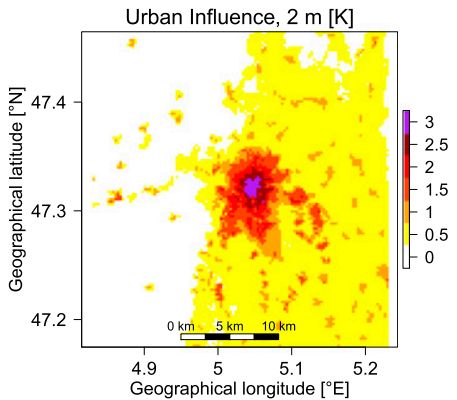

(l) SON, Reference

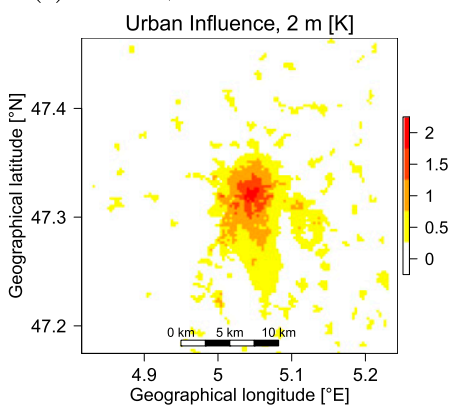


(a) DJF

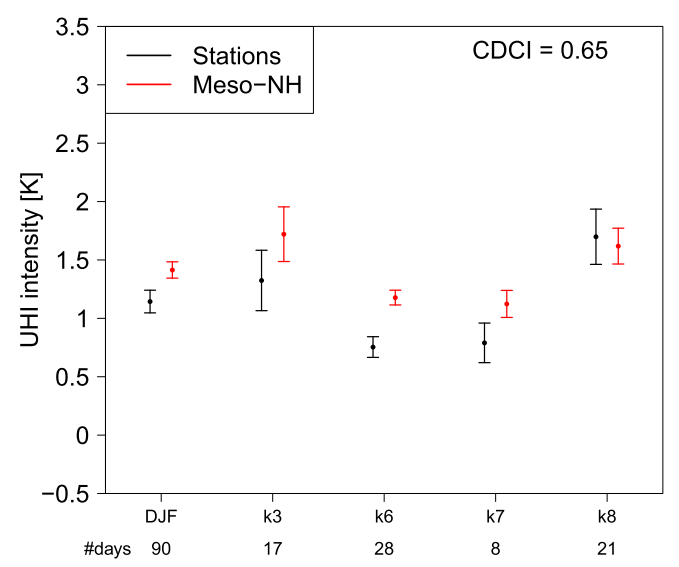

(c) JJA

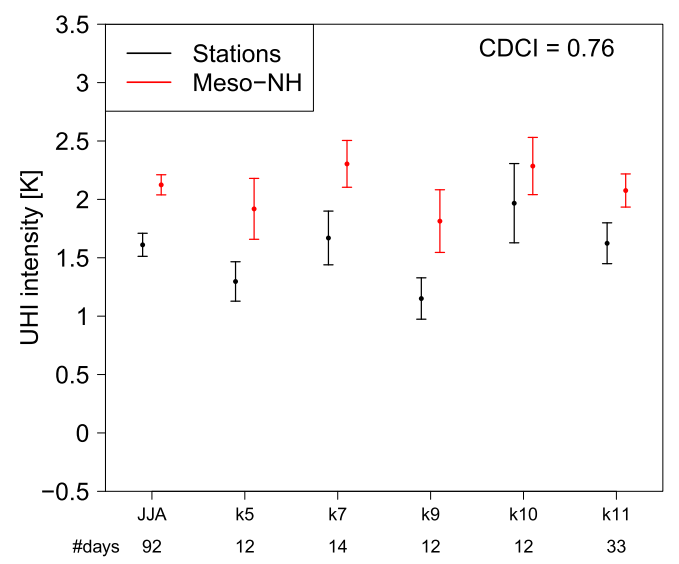

(b) MAM

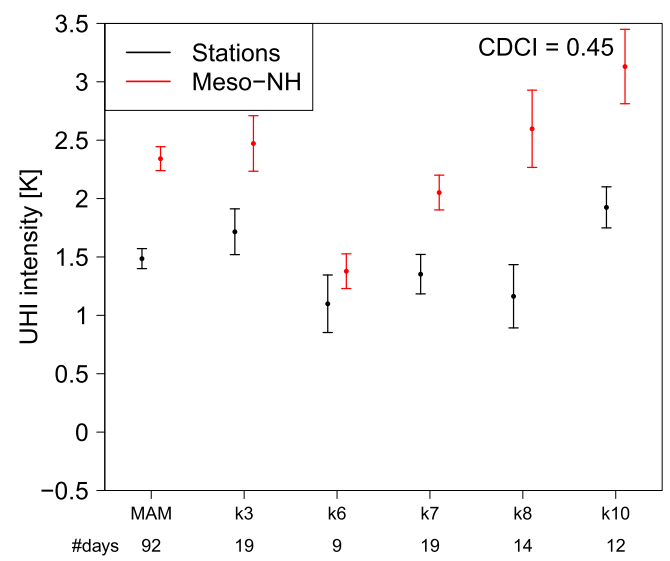

(d) $\mathrm{SON}$

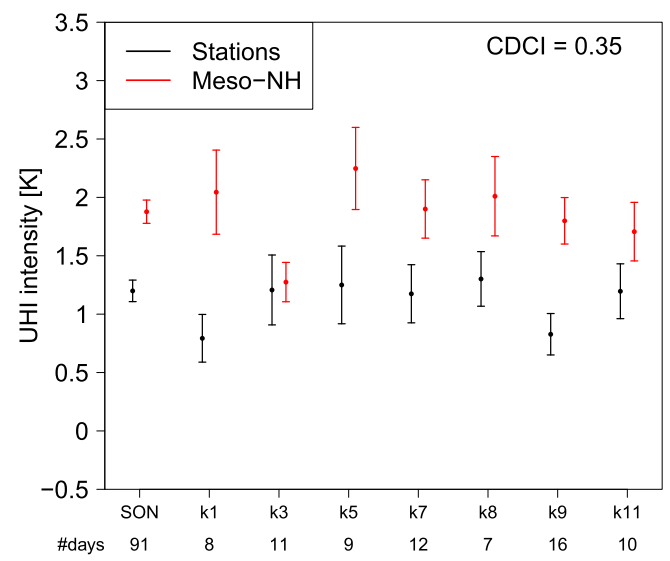

FIG. 7. Simulated and observed nocturnal ( 2 to 5 local time) UHI intensity in Toulouse per season and local weather type. The point depicts the mean, the errorbar the standard deviation of the mean.

the same relevance if only one day is taken to represent each LWT per season.

\section{e. Sensitivity of near-surface air temperature to plane area building density}

Evaluation of the UHI intensity is limited by the availability of stations representative for the rural environment, especially for Toulouse. The objective of this section is to quantify whether Meso-NH accurately captures the sensitivity of the near-surface air temperature on the plane area building density, which is one of the most relevant urban morphology parameters. For Toulouse, only the urban ministation network is used to make sure that all temperature values are measured at the same height above ground. The simulated and observed values of air temperature at the different stations are displayed as a function of the plane area building density for Toulouse (Dijon) in Fig. 9 (Fig. 10). The sensitivity of the near-surface air temperature on the plane area building density is defined here as the slope of the regression lines in the figures. For Toulouse, the simulated sensitivities are slightly overestimated, except for the JJA season (Fig. 9c). This is consistent with the findings for the UHI, but the results show that Meso-NH generally captures the sensitivity well. Interestingly, the residuals from the linear regression displayed in Fig. 9 are consistent between the model and the observations for some stations and for all seasons. The simulated and observed air temperature is relatively high for stations 2 , 10 , and 21. Station 10 is located on a river island, and stations 2 and 21 are located close to the river. For these stations, the nearby water heats the air during the night. This phenomenon is captured by Meso-NH. For stations 1 and 20 , the simulated and observed air temperature is relatively low for all seasons. These stations are far away from the city center. For this reason, they are cooled 
(a) DJF

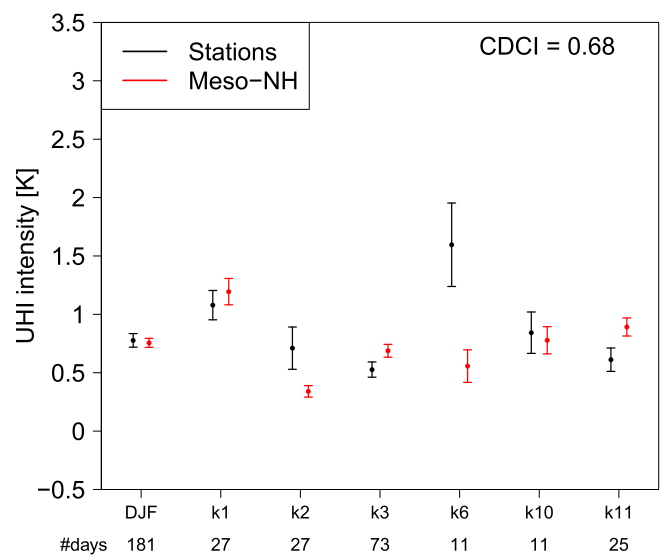

(c) JJA

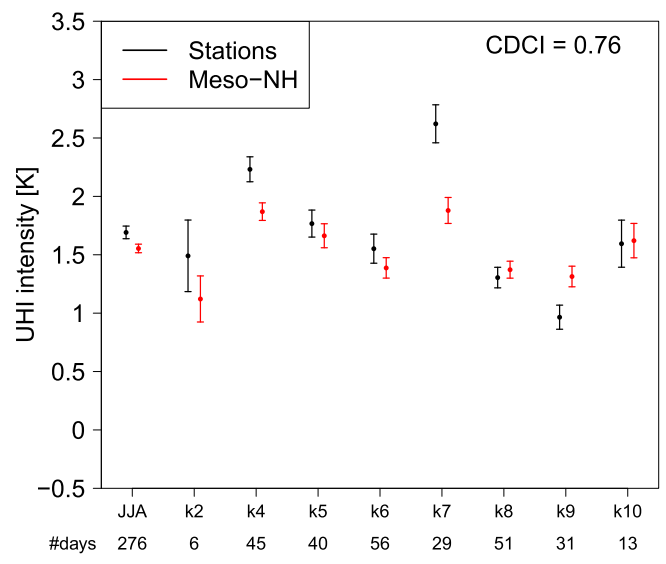

(b) MAM

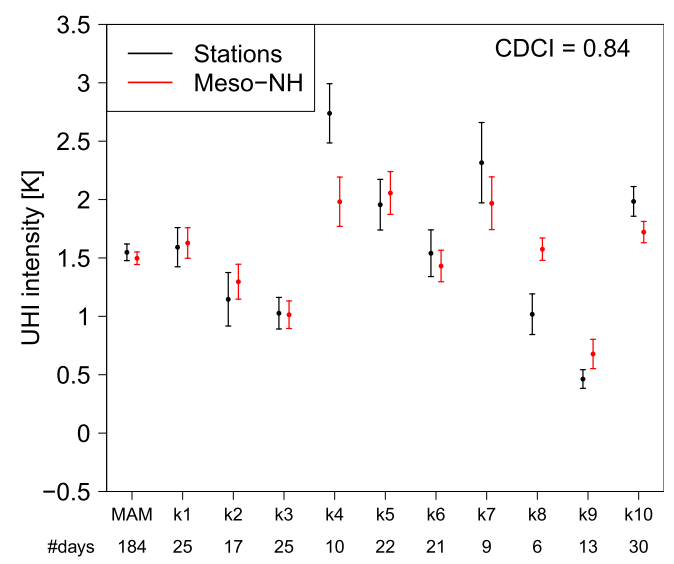

(d) SON

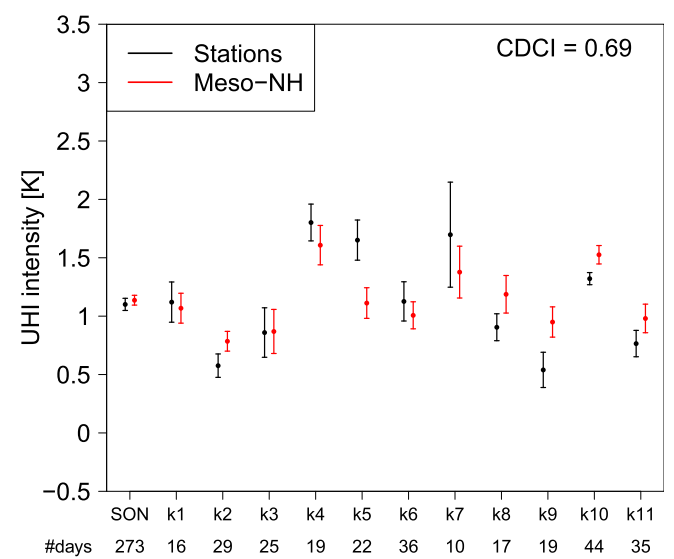

FIG. 8. As in Fig. 7, but for Dijon.

by advection from the adjacent rural areas. This is captured by Meso-NH and consistent with the findings of Kwok et al. (2019). Interestingly, station 15, which is located about $100 \mathrm{~m}$ higher than the other stations is not an outlier, probably due to the presence of inversions during the night.

For Dijon, the sensitivity of near-surface air temperature to plane area building density is captured, which is consistent with the findings for the UHI. An interesting model deficiency for Dijon is that Meso-NH does not capture that stations $2,10,12,27,30,40$, and 41 , which are located between the end of a valley of the Morvan low mountain range and the city center measure relatively lower air temperature in JJA (Fig. 10c). This might be due to a shortcoming of Meso-NH in simulating katabatic flows from the low mountain range toward the city. The too-coarse vertical resolution of $20 \mathrm{~m}$ (first model level in $10 \mathrm{~m}$ above ground) could be the reason.

\section{f. Influence of the UHI on building energy consumption}

The influence of the UHI on building energy consumption is investigated for Toulouse, since an inventory for the

TABLE 8. Results for evaluation measures quantifying the contributions of the statistical and the dynamical uncertainty. STAT: Statistical uncertainty arising from using one single day to represent each LWT per season, DYNA: dynamical uncertainty, and STAT-DYNA: both uncertainties.

\begin{tabular}{lcc}
\hline \hline & Bias $(\mathrm{K})$ & Rmse (K) \\
\hline STAT & Toulouse & \\
DYNA & 0.0 & 1.4 \\
STAT-DYNA & 0.4 & 1.0 \\
& 0.4 & 1.4 \\
STAT & Dijon & \\
DYNA & -0.1 & 1.1 \\
STAT-DYNA & -0.1 & 0.8 \\
\hline
\end{tabular}


(a) DJF

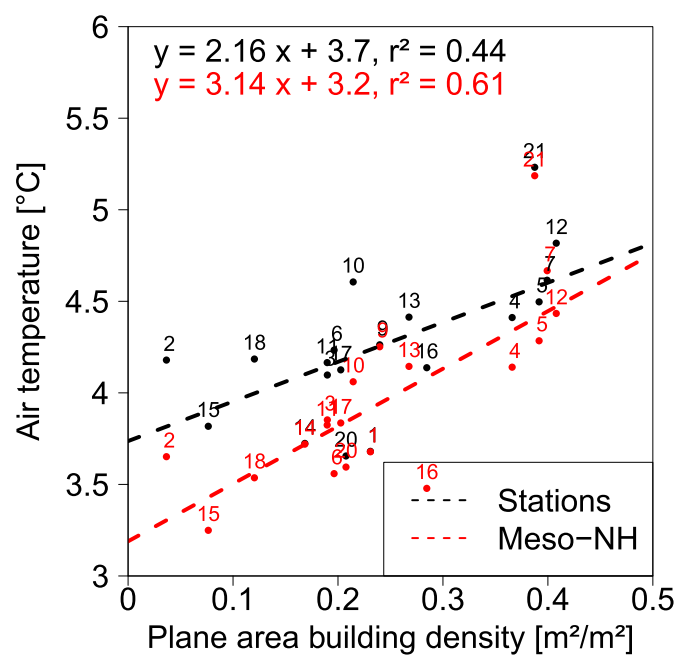

(c) JJA

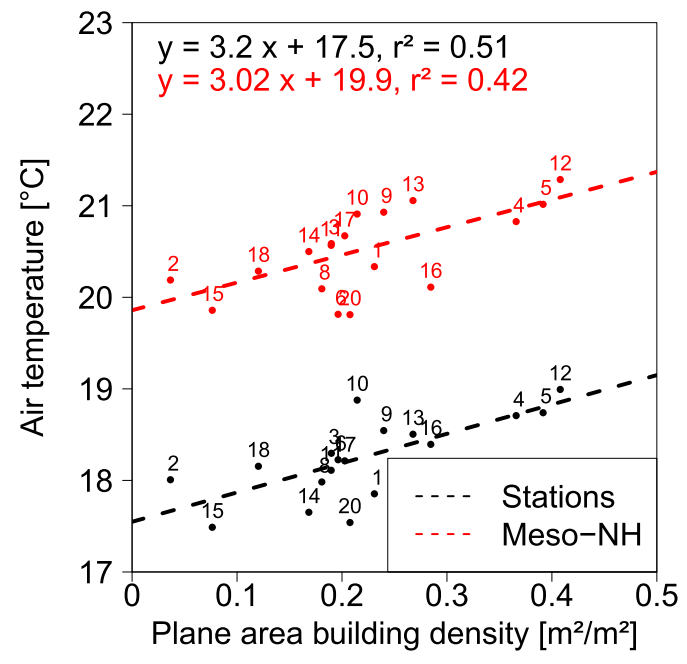

(b) MAM

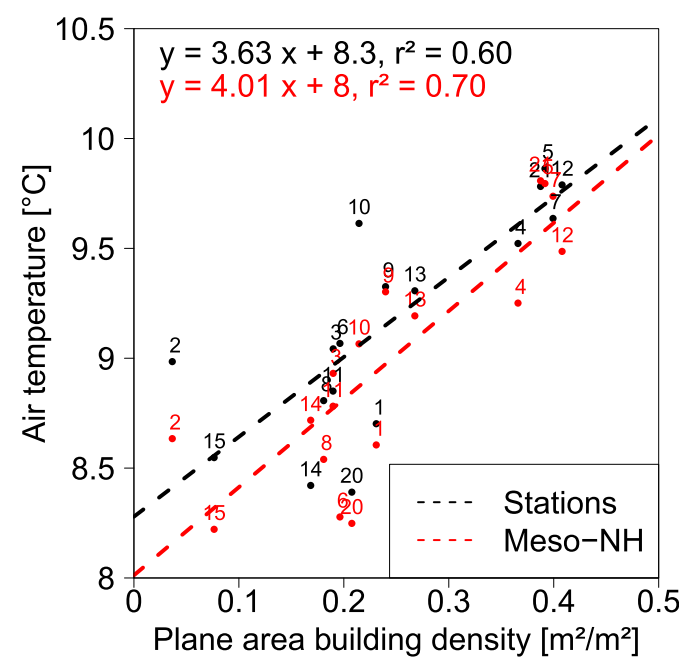

(d) $\mathrm{SON}$

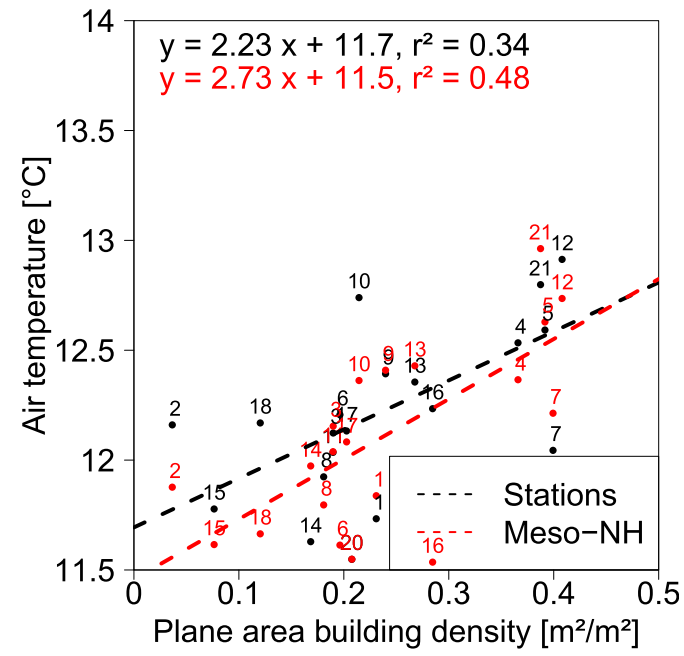

FIG. 9. Sensitivity of near-surface air temperature to plane area building density for Toulouse.

time period of the CAPITOUL campaign is available for a domain of $15 \mathrm{~km} \times 15 \mathrm{~km}$ covering the center of Toulouse (Pigeon et al. 2007). Only the influence of the UHI on heating energy consumption can be investigated, since there has been very little air conditioning use in Toulouse during summer 2004. Figure 11a displays the spatial distribution of the anthropogenic heat flux due to the simulated heating energy consumption for DJF 2004-05 for a simulation when the urban influence on air temperature is neglected (NO-UI). The highest values $\left(>50 \mathrm{~W} \mathrm{~m}^{-2}\right)$ are simulated in central Toulouse, which is no surprise, since the density of heated floor space is highest in this area. The superposition of the
$\mathrm{UI}^{\operatorname{sim}}(x, d)$ patterns from the long-term Meso-NH integration leads to a reduction of the building energy consumption of about $5 \mathrm{~W} \mathrm{~m}^{-2}$ in central Toulouse (Fig. 11b). This corresponds to $10 \%-15 \%$ of the absolute values (Fig. 11c). In the suburban areas, the UHI reduces the heating energy consumption by $0 \%-5 \%$.

Figure 12 displays the time series of daily total (heating and electrical appliances) building energy consumption averaged for the domain displayed in Fig. 11. The simulation results are compared to the inventory of Pigeon et al. (2007). The inventory energy consumption exhibits a strong annual cycle. It is low in the warm season and strongly increases during the domestic 
(a) DJF

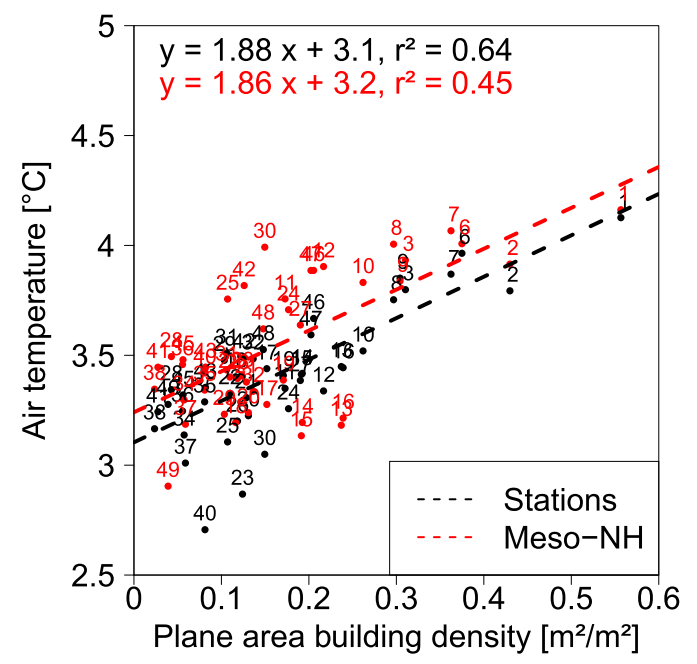

(c) JJA

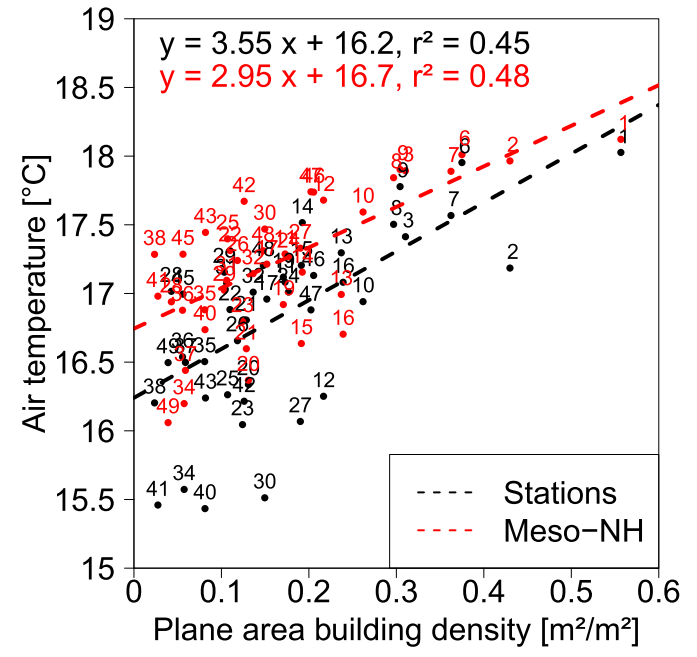

(b) MAM

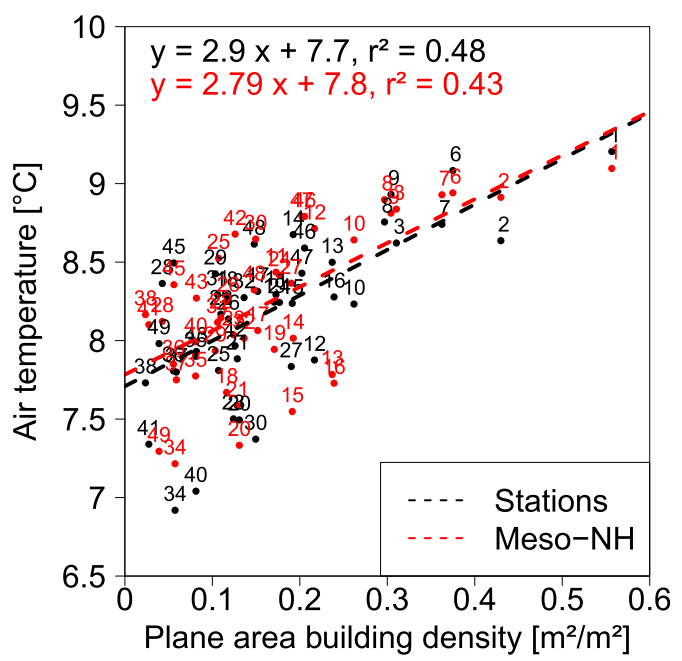

(d) $\mathrm{SON}$

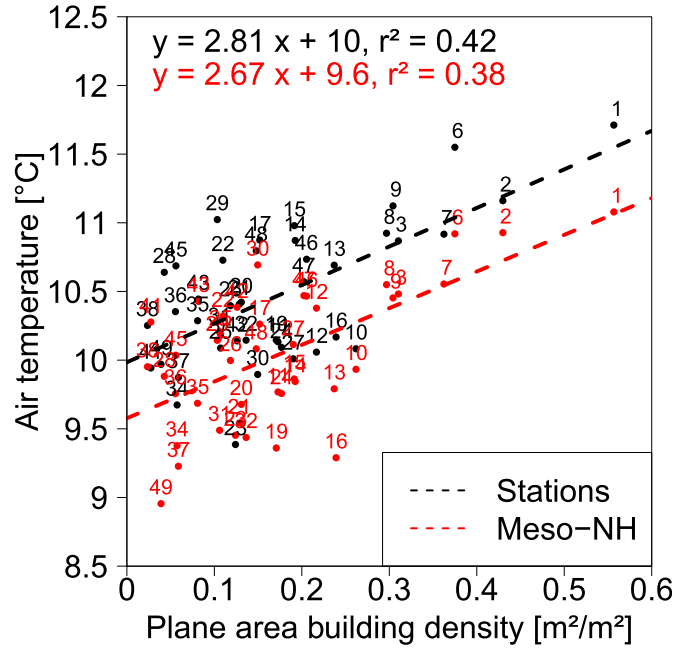

FIG. 10. As in Fig. 9, but for Dijon.

heating period, during which it varies strongly with air temperature. The coupled Meso-NH-TEB simulation (Fig. 12a) captures the time series of building energy consumption. The simulations conducted in offline mode forced with the observed meteorological data and considering the reference time series of $\mathrm{UI}^{\operatorname{sim}}(x, d)$ from the long-term Meso-NH integration are of similar quality to those of the coupled simulation (Fig. 12b). It is further investigated whether the use of the simulated UI patterns for the LWT centroid days (WT-CENT-UI; Fig. 12c) instead of the reference $\mathrm{UI}^{\operatorname{sim}}(x, d)$ time series degrades the model performance. No relevant differences of the simulated building energy consumption are found compared to the simulation with the reference UI patterns.

\section{Conclusions and outlook}

This study describes a statistical-dynamical downscaling for the urban heat island and building energy consumption. It is based on short-term numerical integrations of a mesoscale atmospheric model for a selection of local weather types (LWT) to calculate the urban heat island effect and long-term numerical integrations of an urban canopy model to calculate the building energy consumption. The uncertainties of this method related to the LWT approach (statistical 
(a)

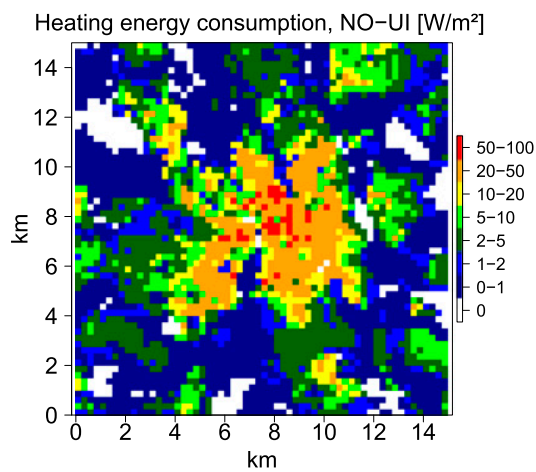

(b)

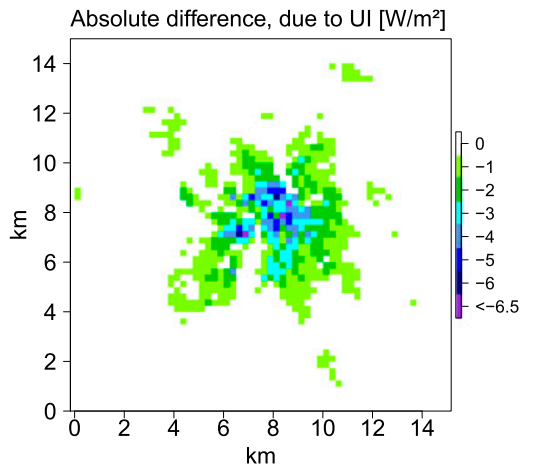

(c)

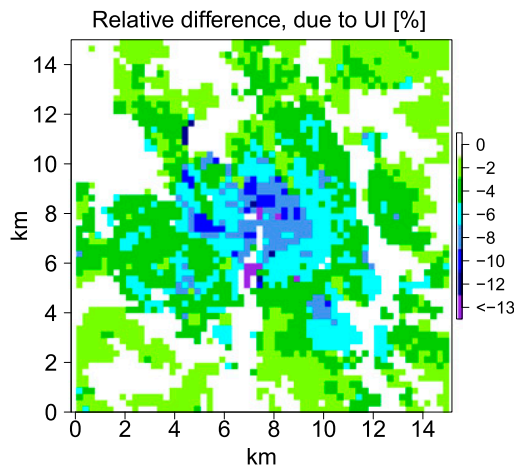

FIG. 11. (a) Simulated anthropogenic heat flux due to heating energy consumption in the $15 \mathrm{~km} \times 15 \mathrm{~km}$ domain covering the center of Toulouse during DJF 2004-05. (b),(c) Absolute and relative difference due to the urban influence on air temperature (UI).

uncertainty) and due to the employed mesoscale model Meso-NH (dynamical uncertainty) were analyzed for two French cities (Toulouse and Dijon). Meso-NH captures the seasonal average nocturnal UHI intensity for Dijon, but it overestimates the UHI intensity during the transition seasons for Toulouse. For both cities and all seasons, the relationship between the UHI intensity and the LWT is captured on average. This means that for LWT with relatively high (low) observed UHI intensity, Meso-NH tends to simulate a relatively high (low) UHI intensity. However, some model deficiencies have been identified. They are related to an underestimation of the simulated UHI intensity for LWT with a relatively high UHI intensity. For these LWT, the near-surface air temperature measurements at the rural stations are biased by urbanization. This can be due to the too-coarse spatial resolution of the mesoscale model $(250 \mathrm{~m} \times 250 \mathrm{~m})$, which is not necessarily representative for the immediate vicinity of the stations. An interesting finding is that the simulated UHI intensity is closer to the observations for Dijon, where the elevation differences between the urban and rural stations are lower and the rural and urban stations measure at the same height above ground. This suggests that apparent model deficiencies for Toulouse can also be due to a less robust definition of the observed UHI for this city. For both cities, the statistical uncertainty is of a similar magnitude as the dynamical uncertainty if only one day is simulated to represent one LWT. Simulating 3-6 days for each LWT can considerably reduce the statistical uncertainty and is therefore recommended. The UHI reduces the simulated building energy consumption by about $10 \%$ in the center of Toulouse; it should therefore be taken into account during the production of high-resolution maps on building energy consumption. (a) Meso-NH-TEB

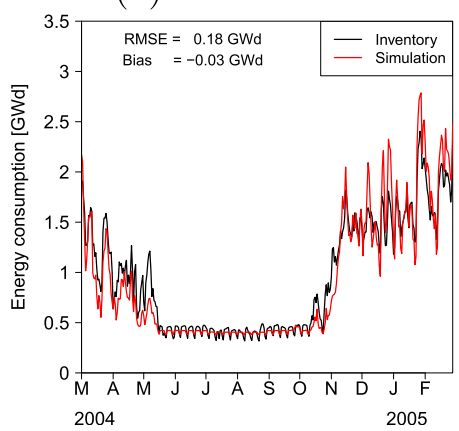

(b) TEB-Offline $+U I^{\operatorname{sim}}(x, d)$

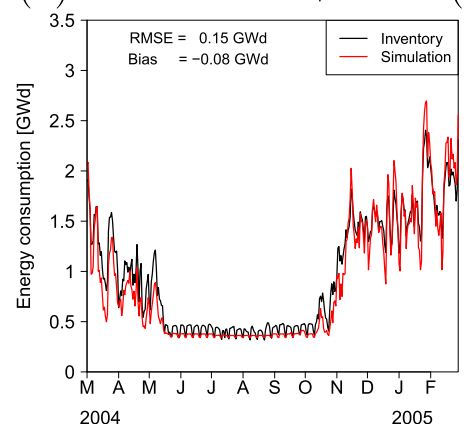

(c) TEB-Offline $+U I^{\operatorname{sim}}\left(x, d_{k}^{c}\right)$

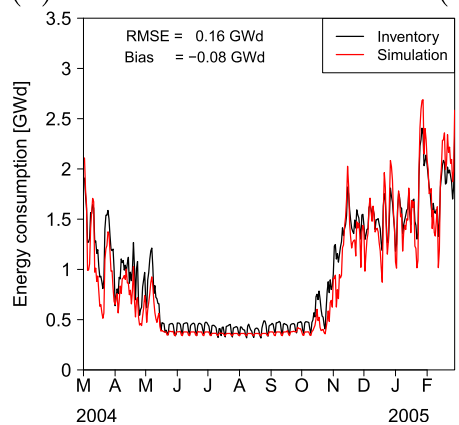

FIG. 12. Time series of daily values of building energy consumption averaged for the domain shown in Fig. 11. The inventory is taken from Pigeon et al. (2007). (a) TEB coupled with Meso-NH, (b) offline simulation with superposition of the spatial distribution of the urban influence on air temperature (UI) obtained from the long-term Meso-NH-TEB simulation to the rural forcing data, and (c) as in (b), but superposing using the simulated UI for the LWT centroid day $\left[\mathrm{UI}^{\mathrm{sim}}\left(x, d_{k, \text { seas }}^{c}\right)\right]$. 
Future work on the statistical-dynamical downscaling method could investigate whether there is an added value of superposing the urban influence on the downwelling longwave radiation to the forcing data. Furthermore, the application of such a downscaling method in cities with more complex topography should be tested and potential issues related to coastal or mountain effects investigated. For cities larger than those investigated in the present study, the urban influence on air temperature may be of relevance even in rural areas adjacent to the city. It could be investigated whether taking this effect into account would change thermal climate indicators or building energy consumption in a relevant manner in rural areas. An application of the downscaling to future climate conditions is challenging since the changes in parameters such as soil moisture between historical and future climate are not represented by the local weather types. Therefore, dynamical simulations will have to be made for future climate conditions, which creates the challenge of constructing forcing data for the mesoscale model based on climate model results.

In the follow-up of the present study, the presented statistical dynamical downscaling will be applied to about 50 French cities using high-resolution analysis data from the AROME France model (Seity et al. 2011) to select the LWT (Jougla et al. 2019). The results allow comparison of the urban heat island intensity of a variety of French cities of different size, geographical situation, and regional climate using a homogeneous modeling approach and the homogeneous MApUCE dataset on urban form and functioning. The urban heat island and building energy data can also be combined with data on sociodemography or public health to calculate population exposure and quantify the vulnerability of the population. Urban climatic maps will be derived based on the simulated thermal climate indicators to inform public authorities about the thermal climate at high spatial resolution and to identify districts with large building energy consumption.

Acknowledgments. Jeanine Payart is acknowledged for the preparation of the ECMWF high-resolution operational forecast analyses. This work has received support from the French National Agency of Research for the project Applied Modelling and Urban Planning Laws: Urban Climate and Energy (MApUCE) with the reference ANR-13-VBDU-0004.

\section{REFERENCES}

Badger, J., H. Frank, A. N. Hahmann, and G. Giebel, 2014: Wind-climate estimation based on mesoscale and microscale modeling: Statistical-dynamical downscaling for wind energy applications. J. Appl. Meteor. Climatol., 53, 19011919, https://doi.org/10.1175/JAMC-D-13-0147.1.

Bocher, E., G. Petit, J. Bernard, and S. Palominos, 2018: A geoprocessing framework to compute urban indicators: The MApUCE tools chain. Urban Climate, 24, 153-174, https://doi.org/10.1016/j.uclim.2018.01.008.

Boé, J., and L. Terray, 2008: A weather-type approach to analyzing winter precipitation in France: Twentieth-century trends and the role of anthropogenic forcing. J. Climate, 21, 3118-3133, https://doi.org/10.1175/2007JCLI1796.1.

Bougeault, P., and P. Lacarrère, 1989: Parameterization of orographic induced turbulence in a mesobeta scale model. Mon. Wea. Rev., 117, 1872-1890, https://doi.org/10.1175/ 1520-0493(1989)117<1872:POOITI >2.0.CO;2.

Bourgeois, A., M. Pellegrino, and J.-P. Lévy, 2017: Modeling and mapping domestic energy behavior: Insights from a consumer survey in France. Energy Res. Soc. Sci., 32, 180-192, https:// doi.org/10.1016/j.erss.2017.06.021.

Bueno, B., G. Pigeon, L. K. Norford, K. Zibouche, and C. Marchadier, 2012: Development and evaluation of a building energy model integrated in the TEB scheme. Geosci. Model Dev., 5, 433-448, https://doi.org/10.5194/gmd-5-433-2012.

Cassou, C., M. Minvielle, L. Terray, and C. Périgaud, 2011: A statistical-dynamical scheme for reconstructing ocean forcing in the Atlantic. Part I: Weather regimes as predictors for ocean surface variables. Climate Dyn., 36, 19-39, https://doi.org/10.1007/ s00382-010-0781-7.

Champeaux, J. L., V. Masson, and F. Chauvin, 2005: ECOCLIMAP: A global database of land surface parameters at $1 \mathrm{~km}$ resolution. Meteor. Appl., 12, 29-32, https://doi.org/10.1017/ S1350482705001519.

Crombette, P., S. Le Corre, and C. Tinel, 2014: Traitement d'images satellitaires à très haute résolution spatiale et identification de zones à enjeux dans l'aménagement des trames vertes urbaines. Rev. Fr. Photogramm. Télédétect., 208, 19-25.

Deardorff, J. W., 1980: Stratocumulus-capped mixed layers derived from a three-dimensional model. Bound.-Layer Meteor., 18, 495-527, https://doi.org/10.1007/BF00119502.

Efron, B., 1979: Bootstrap methods: Another look at the jackknife. Ann. Stat., 7, 1-26, https://doi.org/10.1214/aos/1176344552.

Frey-Buness, F., D. Heimann, and R. Sausen, 1995: A statisticaldynamical downscaling procedure for global climate simulations. Theor. Appl. Climatol., 50, 117-131, https://doi.org/ 10.1007/BF00866111.

Fuentes, U., and D. Heimann, 2000: An improved statisticaldynamical downscaling scheme and its application to the alpine precipitation climatology. Theor. Appl. Climatol., 65, 119-135, https://doi.org/10.1007/s007040070038.

Gabriel, K. M. A., and W. R. Endlicher, 2011: Urban and rural mortality rates during heat waves in Berlin and Brandenburg, Germany. Environ. Pollut., 159, 2044-2050, https://doi.org/ 10.1016/j.envpol.2011.01.016.

Hamdi, R., and V. Masson, 2008: Inclusion of a drag approach in the Town Energy Balance (TEB) scheme: Offline 1D evaluation in a street canyon. J. Appl. Meteor. Climatol., 47, 26272644, https://doi.org/10.1175/2008JAMC1865.1.

Hidalgo, J., and R. Jougla, 2018: On the use of local weather types classification to improve climate understanding: An application on the urban climate of Toulouse. PLOS ONE, 13, e0208138, https://doi.org/10.1371/journal.pone.0208138.

, G. Pigeon, and V. Masson, 2008: Urban-breeze circulation during the CAPITOUL experiment: Observational data 
analysis approach. Meteor. Atmos. Phys., 102, 223-241, https://doi.org/10.1007/s00703-008-0329-0.

——, V. Masson, and C. Baehr, 2014: From daily climatic scenarios to hourly atmospheric forcing fields to force soil-vegetation-atmosphere transfer models. Front. Environ. Sci., 2, 40, https://doi.org/10.3389/fenvs.2014.00040.

Hoffmann, P., and K. H. Schluenzen, 2013: Weather pattern classification to represent the urban heat island in present and future climate. J. Appl. Meteor. Climatol., 52, 2699-2714, https://doi.org/10.1175/JAMC-D-12-065.1.

, O. Krueger, and K. H. Schluenzen, 2012: A statistical model for the urban heat island and its application to a climate change scenario. Int. J. Climatol., 32, 1238-1248, https:// doi.org/10.1002/joc. 2348 .

— , R. Schoetter, and K. Schlünzen, 2018: Statistical-dynamical downscaling of the urban heat island in Hamburg, Germany. Meteor. Z., 27, 89-109, http://doi.org/10.1127/metz/2016/0773.

Jacob, D., and Coauthors, 2014: EURO-CORDEX: New highresolution climate change projections for European impact research. Reg. Environ. Change, 14, 563-578, https://doi.org/ 10.1007/s10113-013-0499-2.

Joly, D., T. Brossard, H. Cardot, J. Cavailhes, M. Hilal, and P. Wavresky, 2010: Les types de climats en France, une construction spatiale. Cybergeo: Eur. J. Geogr., https://doi.org/ 10.4000/cybergeo. 23155 .

Jougla, R., J. Hidalgo, and B. Pouponneau, 2019: Identification des situations météorologiques locales pour une cinquantaine de villes françaises. La Météorologie, 106, 59-68, https://doi.org/ 10.4267/2042/70370.

Kain, J. S., and J. M. Fritsch, 1990: A one-dimensional entraining/ detraining plume model and its application in convective parameterization. J. Atmos. Sci., 47, 2784-2802, https://doi.org/ 10.1175/1520-0469(1990)047〈2784:AODEPM $\rangle 2.0 . C O ; 2$.

Kwok, Y. T., R. Schoetter, K. K.-L. Lau, J. Hidalgo, C. Ren, G. Pigeon, and V. Masson, 2019: How well does the local climate zone scheme discern the thermal environment of Toulouse (France)? An analysis using numerical simulation data. Int. J. Climatol., 39, 5292-5315, https://doi.org/10.1002/ joc.6140.

Lac, C., and Coauthors, 2018: Overview of the Meso-NH model version 5.4 and its applications. Geosci. Model Dev., 11, 19291969, https://doi.org/10.5194/gmd-11-1929-2018.

Lafore, J. P., and Coauthors, 1998: The Meso-NH atmospheric simulation system. Part I: Adiabatic formulation and control simulations. Ann. Geophys., 16, 90-109, https://doi.org/ 10.1007/s00585-997-0090-6.

Lemonsu, A., V. Masson, L. Shashua-Bar, E. Erell, and D. Pearlmutter, 2012: Inclusion of vegetation in the Town Energy Balance model for modelling urban green areas. Geosci. Model Dev., 5, 1377-1393, https://doi.org/10.5194/gmd-5-1377-2012.

_ R. Kounkou-Arnaud, J. Desplat, J.-L. Salagnac, and V. Masson, 2013: Evolution of the Parisian urban climate under a global changing climate. Climatic Change, 116, 679-692, https:// doi.org/10.1007/s10584-012-0521-6.

Martinez, Y., W. Yu, and H. Lin, 2013: A new statistical-dynamical downscaling procedure based on EOF analysis for regional time series generation. J. Appl. Meteor. Climatol., 52, 935-952, https://doi.org/10.1175/JAMC-D-11-065.1.

Masson, V., 2000: A physically-based scheme for the urban energy budget in atmospheric models. Bound.-Layer Meteor., 94, 357-397, https://doi.org/10.1023/A:1002463829265.

_ J.-L. Champeaux, F. Chauvin, C. Meriguet, and R. Lacaze, 2003: A global database of land surface parameters at $1-\mathrm{km}$ resolution in meteorological and climate models. J. Climate, 16, 1261-1282, https://doi.org/10.1175/1520-0442-16.9.1261.

—_ , and Coauthors, 2008: The Canopy and Aerosol Particles Interactions in Toulouse Urban Layer (CAPITOUL) experiment. Meteor. Atmos. Phys., 102, 135-157, https://doi.org/10.1007/s00703008-0289-4.

— , and Coauthors, 2013: The SURFEXv7.2 land and ocean surface platform for coupled or offline simulation of earth surface variables and fluxes. Geosci. Model Dev., 6, 929-960, https://doi.org/10.5194/gmd-6-929-2013.

Mengelkamp, H.-T., H. Kapitza, and U. Pflüger, 1997: Statisticaldynamical downscaling of wind climatologies. J. Wind Eng. Ind. Aerodyn., 67-68, 449-457, https://doi.org/10.1016/S0167. 6105(97)00093-7.

Najac, J., C. Lac, and L. Terray, 2011: Impact of climate change on surface winds in France using a statistical-dynamical downscaling method with mesoscale modelling. Int. J. Climatol., 31, 415-430, https://doi.org/10.1002/joc.2075.

Noilhan, J., and S. Planton, 1989: A simple parameterization of land surface processes for meteorological models. Mon. Wea. Rev., 117, 536-549, https://doi.org/10.1175/1520-0493(1989) 117〈0536:ASPOLS $\rangle$ 2.0.CO;2.

Oke, T. R., 1973: City size and the urban heat island. Atmos. Environ., 7, 769-779, https://doi.org/10.1016/0004-6981(73) 90140-6.

_ - G. Mills, A. Christen, and J. A. Voogt, 2017: Urban Climates. Cambridge University Press, 546 pp., https://doi.org/10.1017/ 9781139016476.

Pergaud, J., V. Masson, S. Malardel, and F. Couvreux, 2009: A parameterization of dry thermals and shallow cumuli for mesoscale numerical weather prediction. Bound.-Layer Meteor., 132, 83-106, https://doi.org/10.1007/s10546-009-9388-0.

Pigeon, G., D. Legain, P. Durand, and V. Masson, 2007: Anthropogenic heat release in an old European agglomeration (Toulouse, France). Int. J. Climatol., 27, 1969-1981, https://doi.org/10.1002/joc.1530.

—, K. Zibouche, B. Bueno, J. L. Bras, and V. Masson, 2014: Improving the capabilities of the Town Energy Balance model with up-to-date building energy simulation algorithms: An application to a set of representative buildings in Paris. Energy and Buildings, 76, 1-14, https://doi.org/10.1016/j.enbuild.2013.10.038.

Pinto, J. G., C. P. Neuhaus, G. C. Leckebusch, M. Reyers, and M. Kerschgens, 2010: Estimation of wind storm impacts over western Germany under future climate conditions using a statistical-dynamical downscaling approach. Tellus, 62A, 188201, https://doi.org/10.1111/j.1600-0870.2009.00424.x.

Reyers, M., J. G. Pinto, and H. Paeth, 2013: Statistical-dynamical downscaling of present day and future precipitation regimes in the Aksu River catchment in central Asia. Global Planet. Change, 107, 36-49, https://doi.org/10.1016/j.gloplacha.2013.04.003.

Richard, Y., and Coauthors, 2018: How relevant are local climate zones and urban climate zones for urban climate research? Dijon (France) as a case study. Urban Climate, 26, 258-274, https://doi.org/10.1016/j.uclim.2018.10.002.

Roth, M., 2007: Review of atmospheric turbulence over cities. Quart. J. Roy. Meteor. Soc., 126, 941-990, https://doi.org/ 10.1002/qj.49712656409.

Rummukainen, M., 2010: State-of-the-art with regional climate models. Wiley Interdiscip. Rev.: Climate Change, 1, 82-96, https://doi.org/10.1002/wcc.8.

Sailor, D. J., 2011: A review of methods for estimating anthropogenic heat and moisture emissions in the urban environment. Int. J. Climatol., 31, 189-199, https://doi.org/10.1002/joc.2106. 
Schoetter, R., V. Masson, A. Bourgeois, M. Pellegrino, and J.-P. Lévy, 2017: Parametrisation of the variety of human behaviour related to building energy consumption in the Town Energy Balance (SURFEX-TEB v.8.2). Geosci. Model Dev., 10, 2801-2831, https://doi.org/10.5194/gmd10-2801-2017.

Seity, Y., P. Brousseau, S. Malardel, G. Hello, P. Bénard, F. Bouttier, C. Lac, and V. Masson, 2011: The AROME-France convectivescale operational model. Mon. Wea. Rev., 139, 976-991, https:// doi.org/10.1175/2010MWR3425.1.

Stewart, I. D., 2011: A systematic review and scientific critique of methodology in modern urban heat island literature. Int. J. Climatol., 31, 200-217, https://doi.org/10.1002/joc.2141.

Svoboda, J., Z. Chladova, L. Pop, and J. Hosek, 2013: Statisticaldynamical downscaling of wind roses over the Czech Republic.
Theor. Appl. Climatol., 112, 713-722, https://doi.org/10.1007/ s00704-012-0759-y.

Tornay, N., R. Schoetter, M. Bonhomme, S. Faraut, and V. Masson, 2017: Genius: A methodology to define a detailed description of buildings for urban climate and building energy consumption simulations. Urban Climate, 20, 75-93, https://doi.org/10.1016/ j.uclim.2017.03.002.

Tran Anh, Q., and K. Taniguchi, 2018: Coupling dynamical and statistical downscaling for high-resolution rainfall forecasting: Case study of the Red River Delta, Vietnam. Prog. Earth Planet. Sci., 5, 28, https://doi.org/10.1186/s40645-018-0185-6.

Wilby, R. L., J. Troni, Y. Biot, L. Tedd, B. C. Hewitson, D. M. Smith, and R. T. Sutton, 2009: A review of climate risk information for adaptation and development planning. Int. J. Climatol., 29, 1193-1215, https://doi.org/10.1002/joc.1839. 